\title{
A Chitin Synthase with a Myosin-Like Motor Domain Is Essential for Hyphal Growth, Appressorium Differentiation, and Pathogenicity of the Maize Anthracnose Fungus Colletotrichum graminicola
}

\author{
Stefan Werner, ${ }^{1}$ Janyce A. Sugui, ${ }^{1}$ Gero Steinberg, ${ }^{2}$ and Holger B. Deising ${ }^{1}$ \\ ${ }^{1}$ Martin-Luther-Universität Halle-Wittenberg, Institute of Agricultural and Nutritional Sciences, Phytopathology and Plant \\ Protection, Ludwig-Wucherer-Str. 2, D-06099 Halle (Saale), Germany; ${ }^{2}$ Max-Planck-Institute of Terrestrial Microbiology, \\ D-35043 Marburg, Germany
}

Submitted 17 June 2007. Accepted 11 August 2007.

\begin{abstract}
Chitin synthesis contributes to cell wall biogenesis and is essential for invasion of solid substrata and pathogenicity of filamentous fungi. In contrast to yeasts, filamentous fungi contain up to 10 chitin synthases (CHS), which might reflect overlapping functions and indicate their complex lifestyle. Previous studies have shown that a class VI CHS of the maize anthracnose fungus Colletotrichum graminicola is essential for cell wall synthesis of conidia and vegetative hyphae. Here, we report on cloning and characterization of three additional CHS genes, CgChsI, CgChsIII, and CgChsV, encoding class I, III, and V CHS, respectively. All CHS genes are expressed during vegetative and pathogenic development. $\Delta C g C h s I$ and $\Delta C g C h s I I I$ mutants did not differ significantly from the wild-type isolate with respect to hyphal growth and pathogenicity. In contrast, null mutants in the $C g C h s V$ gene, which encodes a CHS with an N-terminal myosin-like motor domain, are strongly impaired in vegetative growth and pathogenicity. Even in osmotically stabilized media, vegetative hyphae of $\Delta C g C h s V$ mutants exhibited large balloon-like swellings, appressorial walls appeared to disintegrate during maturation, and infection cells were nonfunctional. Surprisingly, $\Delta C g C h s V$ mutants were able to form dome-shaped hyphopodia that exerted force and showed host cell wall penetration rates comparable with the wild type. However, infection hyphae that formed within the plant cells exhibited severe swellings and were not able to proceed with plant colonization efficiently. Consequently, $\Delta C g C h s V$ mutants did not develop macroscopically visible anthracnose disease symptoms and, thus, were nonpathogenic.
\end{abstract}

Additional keywords: force measurement, fungal cell wall.

Dedicated to Ralph L. Nicholson (1942-2007).

Corresponding author: H. B. Deising; Telephone: +49-345-5522660; Fax: +49-345-5527120; E-mail: holger.deising@landw.uni-halle.de

Current address of S. Werner: Icon Genetics GmbH, Weinbergweg 22, D06120 Halle (Saale), Germany.

Current address of J. A. Sugui: Laboratory of Clinical Infectious Diseases, National Institute of Allergy and Infectious Diseases, National Institutes of Health, Bethesda, MD 20892, U.S.A.
Chitin, the $\beta$-1,4-linked polymer of $N$-acetylglucosamine, represents a major component of the cell walls of higher fungi and is essential for hyphal growth and rigidity (Bartnicki-Garcia 1968; Cabib et al. 1996). After trans-membrane polymerization of chitin by membrane-localized glycosyl transferases called chitin synthases (CHS), chitin strands are covalently linked with $\beta$-glucan to contribute to a network of four structural cell wall components (i.e., chitin, $\beta-1,3-$ and $\beta-1,6-$ glucan, and mannoprotein) (Kollar et al. 1997; Sietsma and Wessels 1994; Wessels 1993).

The yeast Saccharomyces cerevisiae contains three CHS with distinct cell cycle functions in cell wall expansion, septum formation, and budding (Cabib et al. 1996, 2001). In comparison, the genome of filamentous fungi may contain as many as 10 CHS genes (Miyazaki and Ootaki 1997), grouped in six classes, with CHS of classes III, V, and VI being typical for filamentous fungi (Munro and Gow 2001). Because certain CHS are active during defined developmental stages of Aspergillus nidulans (Lee et al. 2004), one may argue that individual enzymes are required during different stages of complex life cycles and to adapt to different ecological niches (Ruiz-Herrera et al. 2002). Alternatively, different CHS may concertedly contribute to certain processes in vegetative or pathogenic development, with overlapping roles (Roncero 2002). This view is supported by the fact that mutations in single CHS genes often do not cause obvious phenotypes (Motoyama et al. 1994, 1997; Specht et al. 1996), but double and triple mutations result in drastic cell wall defects (Fujiwara et al. 2000; Ichinomiya et al. 2002; Motoyama et al. 1997; Shaw et al. 1991; Wang et al. 2001). With the exceptions of the maize smut fungus Ustilago maydis, the vascular wilt fungus Fusarium oxysporum, and the gray mold fungus Botrytis cinerea, the role of individual CHS in the infection process of plant-pathogenic fungi has not been studied (Madrid et al. 2003; Soulié et al. 2006; Weber et al. 2006). These detailed investigations revealed essential roles of class V CHS (Madrid et al. 2003; Weber et al. 2006), suggesting that these myosin-like CHS are of particular importance for virulence of fungal pathogens.

Colletotrichum graminicola, the causal agent of maize leaf anthracnose and stalk rot, is a severe pathogen that caused considerable yield losses throughout the north-central and eastern United States (Bergstrom and Nicholson 1999; Warren et al. 1973). Differentiation of an appressorium is essential for in- 
fection of intact host tissue (Deising et al. 2000; Mendgen and Deising 1993; Mendgen et al. 1996). During maturation of appressoria of Colletotrichum spp., melanin is incorporated into the cell wall and osmotically active compounds are synthesized to high concentrations. Measurements with optical waveguides indicated that appressoria of $C$. graminicola generate considerable turgor pressure, which is translated into force that is exerted onto an epidermal cell in order to penetrate the host (Bastmeyer et al. 2002; Bechinger et al. 1999). Conceivably, rigid fungal cell walls are thought to be essential to support the high osmotic pressure and direct force during the infection process. Moreover, invasive growth of fungal hyphae in planta requires cell wall synthesis, which further suggests that wall-synthesizing enzymes are of high importance for fungal virulence. Random mutagenesis experiments allowed identifying a mutant of $C$. graminicola with conidia that burst and hyphal apices that swell in media with low osmotic potential (Epstein et al. 1998). According to recent classification (Munro and Gow 2001), the tagged gene encodes a class VI CHS, which is responsible for synthesis of approximately $30 \%$ of the chitin in conidial cell walls (Amnuaykanjanasin and Epstein 2003).

In this article, we report on genetical dissection of chitin synthesis in C. graminicola and show that $\mathrm{CgChsV}$, a chitin synthase with a myosin-like motor domain, is essential for hyphal growth, infection structure differentiation, and pathogenicity.

\section{RESULTS}

\section{Chitin synthesis is required}

for hyphal morphology, appressorium formation, and pathogenicity of $C$. graminicola.

Chitin represents a major cell wall polymer in filamentous fungi and is synthesized at the apex of a growing hypha. To localize chitin, vegetative hyphae of $C$. graminicola were stained with the tetramethylrhodamine isothiocyanate (TRITC)-conjugated chitin-specific lectin wheat germ agglutinin (WGA) (Fig. 1). Hyphae growing with few branches (Fig. 1A) as well as highly branched hyphae (Fig. 1B) showed strongly fluorescing apices (arrows), indicating chitin biosynthesis and deposi- tion of newly formed chitin at hyphal tips. However, some apices were not decorated by WGA (compare hyphae marked by arrowheads in fluorescence images of Figure 1A and B), suggesting either that these hyphae were not actively growing or that the chitin was not accessible to the agglutinin, due to modification or masking of the polymer.

To investigate the importance of chitin for rigidity and function of cell walls of the maize pathogen $C$. graminicola, saprophytic and pathogenic development of the fungus was assessed in the presence of the competitive CHS inhibitor nikkomycin Z (Fig. 2). In liquid media, branched vegetative hyphae developed (Fig. 2A, left image). When grown in medium containing $50 \mu \mathrm{M}$ nikkomycin $\mathrm{Z}$, large hyphal swellings filled with vacuoles occurred along hyphae at irregular intervals (Fig. 2A, middle image), suggesting that the inhibition of CHS resulted in cell wall defects that were unevenly distributed along the hypha. Occasionally, swellings were closely associated and formed chains of protrusions (Fig. 2A, right image). These observations clearly indicate that chitin represents an essential structural polymer of vegetative hyphae. Next, we assessed the importance of chitin synthesis in infection structures differentiated in vitro and for infection competence on maize leaves (Fig. 2B through D). On hydrophobic hard surfaces such as polyester, conidia germinate, form a short germ tube, and differentiate a melanized appressorium (Deising et al. 2000). Already at the lowest nikkomycin $\mathrm{Z}$ concentration tested $(10 \mu \mathrm{M})$, approximately $60 \%$ of the appressoria were distorted and showed drastically increased diameters (Fig. 2B and C). Although some of the enlarged appressoria were still melanized (Fig. 2C, arrow), others failed to melanize and had collapsed (Fig. 2C, white arrowhead). Occasionally, swollen germ tubes also were observed (Fig. 2C, black arrowhead). Increasing the nikkomycin $\mathrm{Z}$ concentration to $100 \mu \mathrm{M}$ only led to minor increases of the portion of abnormal structures (Fig. 2B). Importantly, conidial germination rates were not significantly affected by the inhibitor at the concentrations tested (Fig. 2B).

Because differentiation of functional appressoria is essential for invasion of host leaves, we anticipated that inhibition of chitin synthesis would affect not only infection-related morphogenesis but also infection rates and disease symptom de-
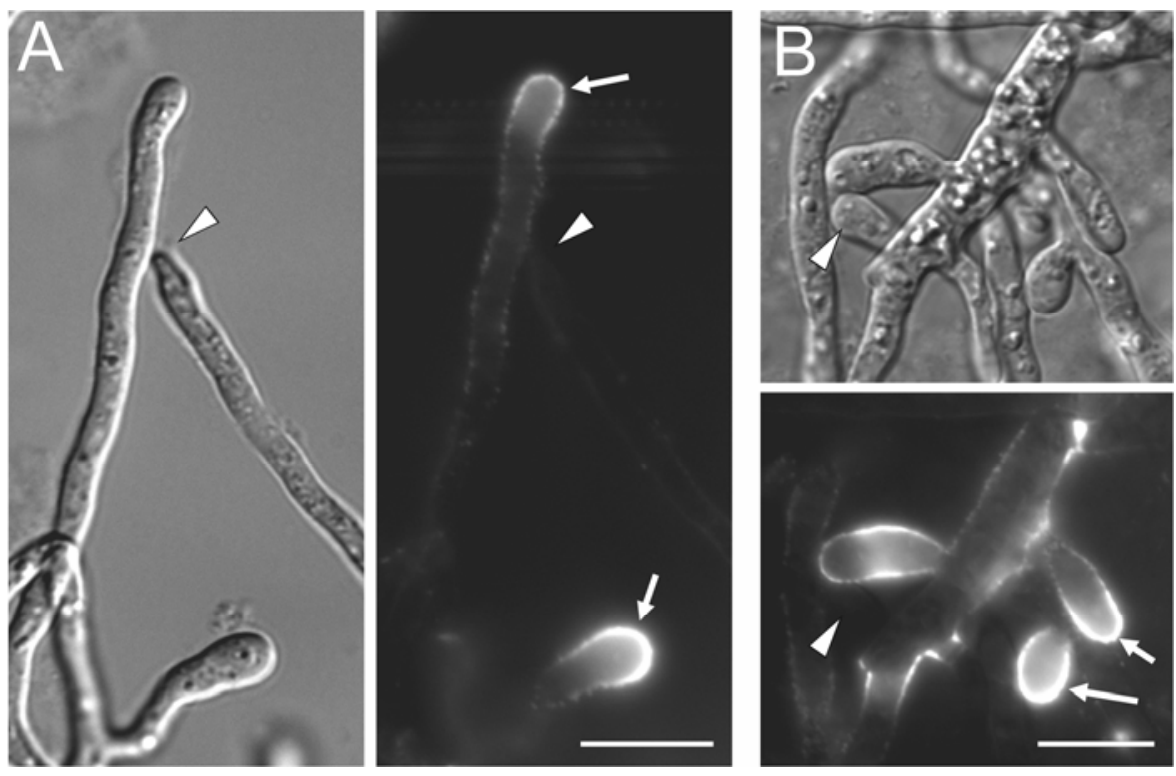

Fig. 1. Localization of chitin by labeling with wheat germ agglutinin (WGA). A, Newly synthesized chitin localized at the apices of rapidly growing hyphae was stained with tetramethylrhodamine isothiocyanate-labeled WGA (right image, arrow). Some hyphae did not show apical fluorescence (compare arrowheads in left differential interference contrast (DIC) and right fluorescence images). B, Localization of chitin in older, heavily branched parts of the mycelium. Arrows indicate WGA-labeled hyphal tips; arrowheads in upper DIC and lower fluorescence images indicate nonfluorescing apices. Bars are $10 \mu \mathrm{m}$. 
velopment. Indeed, increasing inhibitor concentrations resulted in reduction of anthracnose symptom severity, and no symptoms were visible when the infection droplets contained 100 $\mu \mathrm{M}$ nikkomycin Z (Fig. 2D). As expected, clear anthracnose symptoms occurred in the absence of the chitin synthase inhibitor, and control leaves mock inoculated with distilled water did not develop disease symptoms (Fig. 2D). Taken together, these data suggest that chitin synthesis is indispensable for vegetative growth and pathogenicity of $C$. graminicola.

\section{Identification of CHS from C. graminicola.}

To isolate CHS genes of $C$. graminicola, we performed polymerase chain reaction (PCR) studies with degenerate primers designed to amplify class I to III and class IV to VI genes. Four PCR fragments of $619,638,660$, and 710 bp were obtained. Sequence analyses of the 710-bp PCR fragment amplified with primers CHS3 and CHS4 showed that it corresponds to a part of the class VI CgChsVI gene originally designated chsA (Amnuaykanjanasin and Epstein 2003). This gene has been studied in detail previously; therefore, it was not further ana- lyzed here. The 619- and 638-bp PCR fragments amplified with primers CHS1 and CHS2 were used to screen a cosmid library. Purified cosmid clones contained the complete coding regions of a class I ( $C g C h s I)$ and a class III $(C g C h s I I I)$ CHS gene (classification was done according to Munro and Gow [2001]; see also Mellado and associates [2003] and Takeshita and associates [2006]). The complete sequences of the CHS gene of $C$. graminicola studied here are available under GenBank accession numbers AY052545 (CgChsI), AY052546 (CgChsIII), and

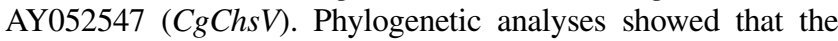
class I and class III CHS are most closely related with the corresponding enzymes NcChs3 and NcChs1 of Neurospora crassa, with 74 and $71 \%$ amino acid identity, respectively (Fig. 3A). The proteins consist of 899 and 912 amino acids, respectively, and show a typical CHS core region (Nagahashi et al. 1995). Hydropathy plots suggest that both enzymes have eight transmembrane domains (Fig. 3B). In addition to the class I and III CHS genes, we identified a class V CHS gene of $C$. graminicola, designated $C g C h s V . C g C h s V$ has a 5,709-bp open reading frame, which is interrupted by two introns (nucleotides 311 to
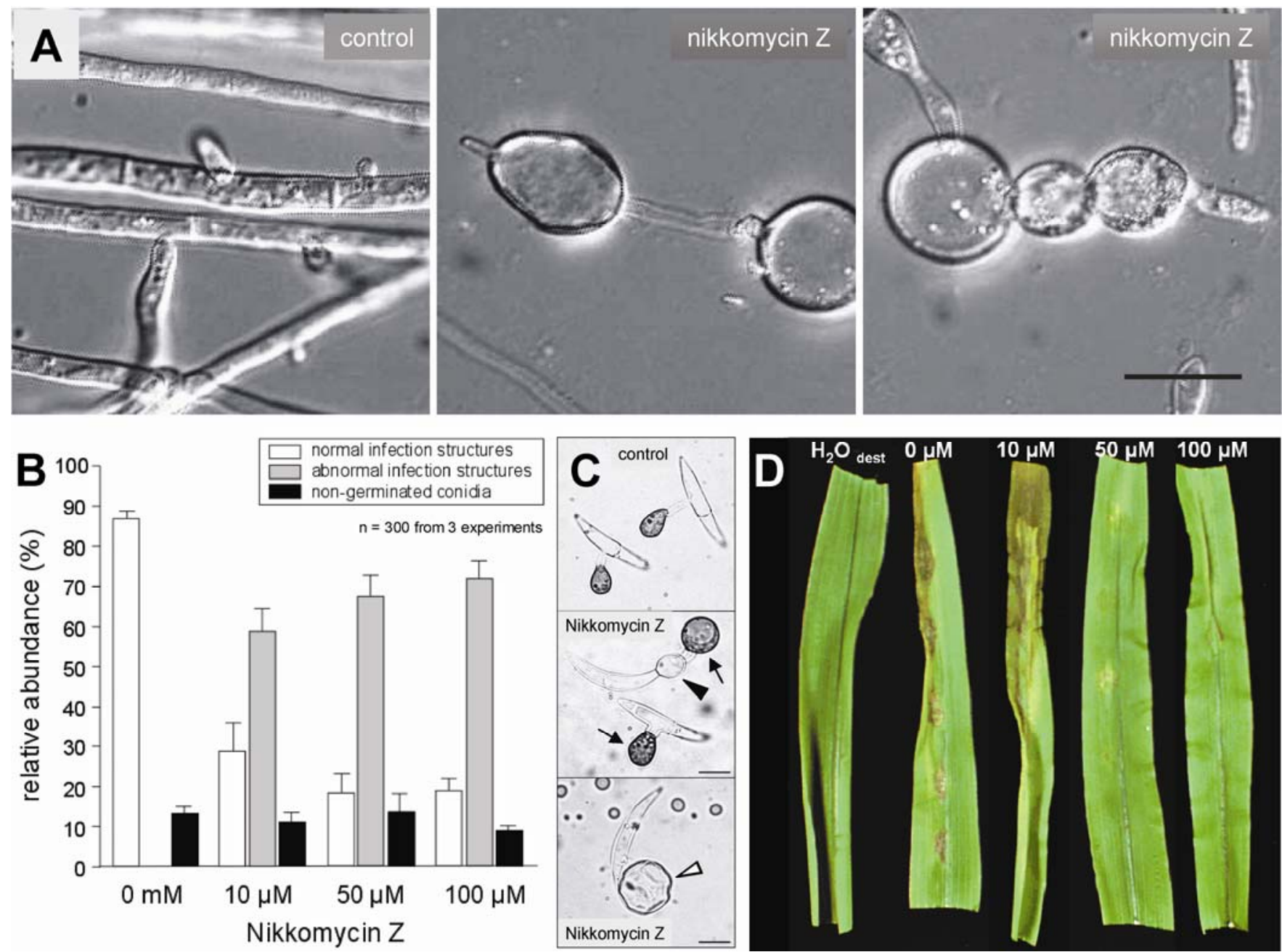

Fig. 2. Effect of the chitin synthase inhibitor nikkomycin $\mathrm{Z}$ on vegetative development and pathogenesis of the maize pathogen Colletotrichum graminicola. A, Effect of nikkomycin Z on vegetative hyphae. Hyphae of the wild-type strain CgM2 were grown in liquid complete medium in the absence (control) or in liquid complete medium supplemented with $50 \mu \mathrm{M}$ inhibitor (nikkomycin Z). Individual hyphal swellings (middle) or chains of bulbs (right) can be observed in the presence of the inhibitor. Bar represents $20 \mu \mathrm{m}$. B and $\mathbf{C}$, Effect of nikkomycin Z on infection structure differentiation. Wild-type conidia were allowed to germinate and differentiate appressoria in the presence of different nikkomycin $\mathrm{Z}$ concentrations for $24 \mathrm{~h}$, and rates of distorted structures were scored. Melanized appressoria formed at the tip of short germ tubes of untreated controls (control). In the presence of the inhibitor at $10 \mu \mathrm{M}$ or higher concentrations, germ tubes (nikkomycin Z, black arrowhead) or appressoria (nikkomycin Z, white arrowhead) swell and appressoria sometimes fail to melanize and collapse. Bar represents $10 \mu \mathrm{m}$. D, Inhibition of disease symptom development by nikkomycin Z. Leaves were inoculated with conidial suspensions containing increasing concentrations of the chitin synthase inhibitor nikkomycin Z. In the presence of $100 \mu \mathrm{M}$ nikkomycin, anthracnose disease symptoms did not occur. Likewise, leaves mock inoculated with water did not show disease symptoms. 
367 and 5,624 to 5,677). This derived protein, like CgChsVI, has an N-terminal myosin-like motor domain and a CHS core region at the C-terminus (Fig. 3B). The myosin motor domain of $\mathrm{CgChsV}$ shows strong similarity $(2.2 \mathrm{e}-115)$ with the myosin motor consensus sequence and has a P-loop ATP binding site (GESGSG) as well as the regulatory IQ motif. In comparison, the myosin-like domain of $\mathrm{CgChsVI}$ is much shorter and shows only limited similarity with the myosin motor consensus sequence (2.9 e-7). For both CHS of C. graminicola with myosinlike motor domains, six transmembrane domains have been predicted (Fig. 3B). In total, the proteins contain 1,866 ( $\mathrm{CgChsV})$ and $1,783(\mathrm{CgChsVI})$ amino acids. The expression profile of the four CHS genes identified in C. graminicola was studied by reverse-transcription (RT)-PCRs with RNA isolated from vegetative hyphae and pre- and post-penetration stages of pathogenic development (i.e., from in vitro infection structures that had formed appressoria and from infected leaves). All genes were expressed at all stages of fungal development investigated (Fig. $3 \mathrm{C})$.

\section{Generation of $\Delta C g C h s I, \Delta C g C h s I I I$,} and $\Delta C g C h s V$ mutants.

To functionally characterize $C g C h s I, C g C h s I I I$, and $C g C h s V$, mutants were generated in which a part of the CHS coding region was replaced by the hygromycin phosphotransferase (hph) gene of Escherichia coli. As an example, targeted inactivation of $C g C h s V$ is shown (Fig. 4). The knock-out (KO) vector consisted of $974 \mathrm{bp}$ of the $C g C h s V$ gene $5^{\prime}$ and 1,621 bp 3' of the $h p h$ gene (Fig. 4A) and was transformed into the $C$. graminicola wild-type strain $\mathrm{CgM} 2$. In order to discriminate between transformants with homologous and ectopic integration of the KO vector, Southern blot experiments were performed with HindIII-digested DNA from the wild-type CgM2 and different independent transformants. While the wild-type strain showed a single $5.6-\mathrm{kb}$ band hybridizing with the $C g C h s V$ probe, KO mutants exhibited a $7.7-\mathrm{kb}$ band. In addition to the 5.6-kb $C g C h s V$ wild-type band, a high molecular weight band was detected in transformants with ectopically integrated $\mathrm{KO}$ vector (Fig. 4B).

To demonstrate that partial replacement of the $C g C h s V$ gene resulted in failure to synthesize the $C g C h s V$ transcript, RTPCR experiments were performed with total RNA from vegetative hyphae of the wild-type strain $\mathrm{CgM} 2$ and the transformants used in Southern blot experiments. As expected, $C g C h s V$ transcripts were present in the wild-type strain and transformants with ectopically integrated $\mathrm{KO}$ vector, but absent from four transformants with homologous integration of the $\mathrm{KO}$ vector (Fig. 4B). In corresponding gene-deletion experi-
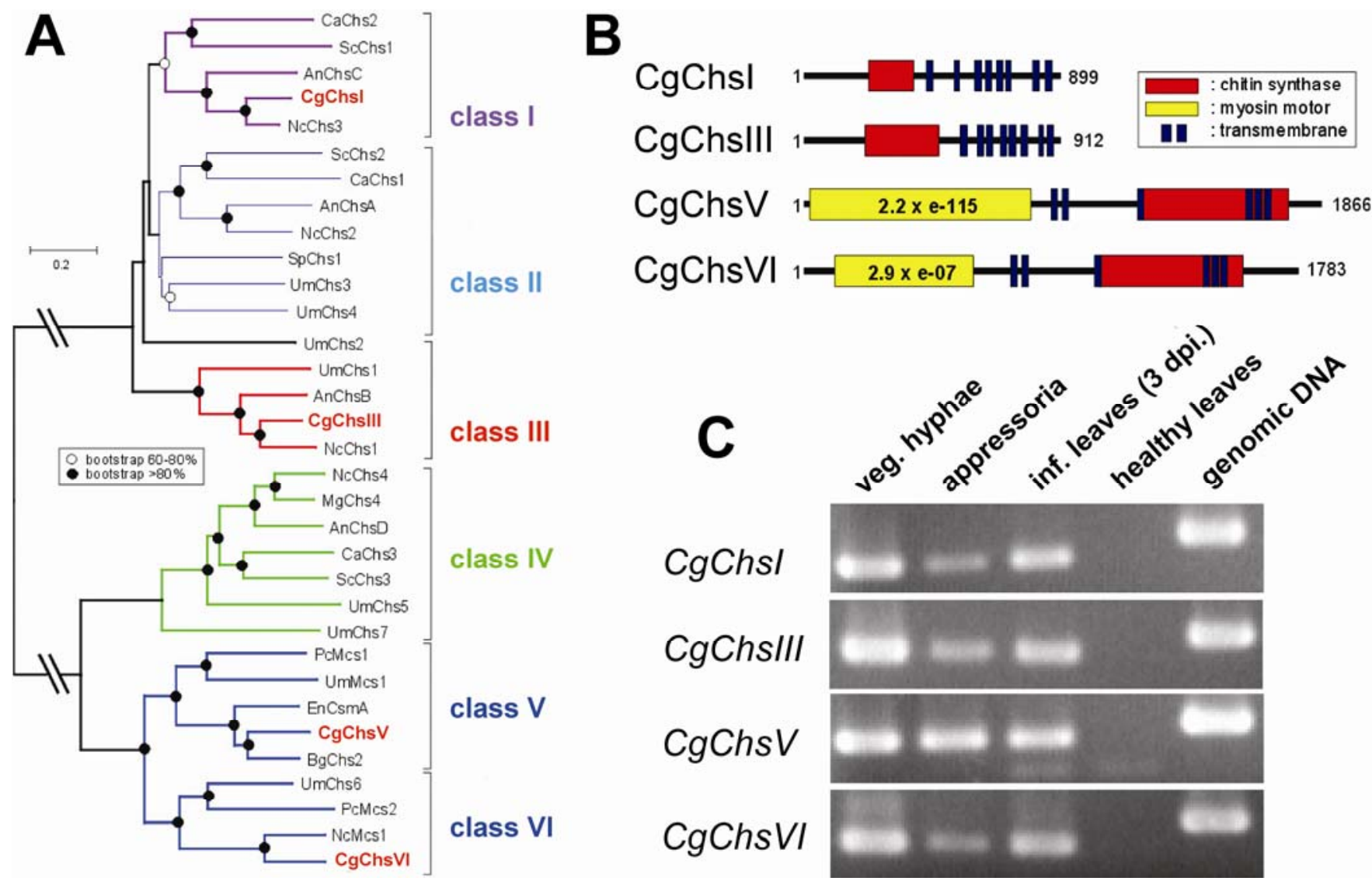

Fig. 3. Sequences and expression pattern of the chitin synthases (CHS) of Colletotrichum graminicola. A, Phylogenetic analysis of fungal CHS. The amino acid sequences of the four CHS of $C$. graminicola (the class VI CgChsVI has been described previously as chsA) (Amnuaykanjanasin and Epstein 2003) were compared with typical enzymes of all known CHS classes. Af, Aspergillus fumigatus; An, A. nidulans; Ao, A. oryzae; Bg, Blumeria graminis; Ca, Candida albicans; $\mathrm{Cg}$, Colletotrichum graminicola; $\mathrm{Mg}$, Magnaporthe grisea; $\mathrm{Nc}$, Neurospora crassa; $\mathrm{Pc}$, Phanerochaete crysosporium; Sc, Saccharomyces cerevisiae; Um, Ustilago maydis; Sp, Schizosaccharomyces pombe. B, Domain organization of the CHS of C. graminicola. Class I and III CHS show a typical CHS core region containing parts that most likely provide the enzymatic activity, and eight transmembrane domains. The class V and class VI CHS also have a typical CHS core region and six transmembrane domains. Both enzymes exhibit a myosin-like motor domain; whereas this domain shows high similarity with the myosin motor consensus sequence in $\mathrm{CgChsV}$, it is truncated in CgChsVI. C, Expression pattern of CHS genes of $C$. graminicola. Reversetranscription polymerase chain reaction assays were performed with total RNA isolated from vegetative hyphae (veg. Hyphae), conidia that had formed appressoria (appressoria), infected leaves 3 days postinfection (inf. leaves ( $3 \mathrm{dpi}$.)), and noninfected leaves (healthy leaves) to visualize transcripts of individual CHS genes. Control PCR reactions were performed with genomic DNA as template (genomic DNA). 
ments, transformants carrying homologous and ectopic integrations of the $\mathrm{KO}$ vector for $\mathrm{CgChsI}$ and $C g C h s I I I$ also were obtained (data not shown). However, $C$. graminicola mutants defective in $C g C h s I$ and $C g C h s I I I$ did not display any obvious phenotype (growth rate, hyphal morphology, and conidiation rates) differing from the wild type and their virulence on maize leaves was not altered (data not shown).

\section{CgChsV confers rigidity}

to vegetative hyphae of $C$. graminicola.

Inactivation of $C g C h s V$ drastically affected vegetative growth of $C$. graminicola (Fig. 5). Although the wild-type strain $\mathrm{CgM} 2$ and transformants with ectopically integrated $\mathrm{KO}$ vector grew comparably well on oatmeal agar (OMA), the $\Delta C g C h s V$ mutant failed to grow on this substratum. However, on OMA osmotically stabilized with $150 \mathrm{mM} \mathrm{KCl}$, growth of the $\triangle C g C h s V$ mutant was partially rescued (Fig. 5A). Under these conditions, wild-type hyphae grew straight with some branching (Fig. 5B). Even in the presence of high osmolyte concentrations, significant cell wall defects were obvious in the $\Delta C g C h s V$ mutant. In some parts of the mycelium, hyphae grew with swellings occurring occasionally (Fig. 5C) whereas, in others, chains of protrusions almost completely lacking filamentous stretches were visible (Fig. 5D). Cell wall defects were reminiscent of those caused by the chitin synthase inhibitor nikkomycin $\mathrm{Z}$, although the latter primarily occurred at the hyphal tips (compare Figs. 2A and 5B through D). Determination of the $\mathrm{N}$-acetyl glucosamine contents suggested that chitin content is reduced by approximately $30 \%$ in $\Delta C g C h s V$ compared with wild-type hyphae (S. Werner, H. B. Deising, and B. Morschbacher, data not shown). Complementation of a
$\Delta C g C h s V$ strain with the entire CgCHSV gene driven by the glyceraldehyde-3-phosphate promoter of A. nidulans complemented growth and hyphal morphology defects of $\Delta C g C h s V$, but did not fully restore its ability to produce conidia (data not shown). These data demonstrate that $\mathrm{CgChsV}$ has essential roles in wall formation in C. graminicola.

\section{CgChsV is essential for appressorium formation but dispensable for hyphopodium development and function.}

Because appressoria need very rigid cell walls to control the high osmotic pressure, it was of interest to see whether or not the $\Delta C g C h s V$ mutant would be able to differentiate morphologically and functionally normal infection cells (Fig. 6). $\triangle C g C h s V$ mutants failed to form acervuli with falcate conidia in regular complete medium (CM); however, in liquid CM supplemented with $0.5 \mathrm{M}$ sucrose, both the wild type and the $\Delta C g C h s V$ mutant produced conidia. Although wild-type conidia were falcate (Fig. 6A), the $\Delta C g C h s V$ mutant formed both falcate and shorter cylindrical conidia (Fig. 6B and C). Even in the presence of $0.5 \mathrm{M}$ sucrose, the wild-type conidia formed a short germ tube (Fig. 6A, arrowheads) and differentiated a melanized appressorium on the surface of polyester sheets (Fig. 6A, arrows). Conidia of the $\Delta C g C h s V$ mutant also germinated in $\mathrm{CM}$ medium with $0.5 \mathrm{M}$ sucrose and formed appressoria. However, $\triangle C g C h s V$ appressoria were severely distorted and the appressorial cell wall appeared to be disintegrated (Fig. 6B, arrow). The fact that germ tubes formed (Fig. 6B, arrowhead) suggests that $\triangle C g C h s V$ conidia do not rupture and release cytoplasm upon germination. Moreover, the size of the distorted cells is comparable with that of wild-type appressoria (compare cells in Figure 6A to C, arrows). The distorted appressoria showed some melanization
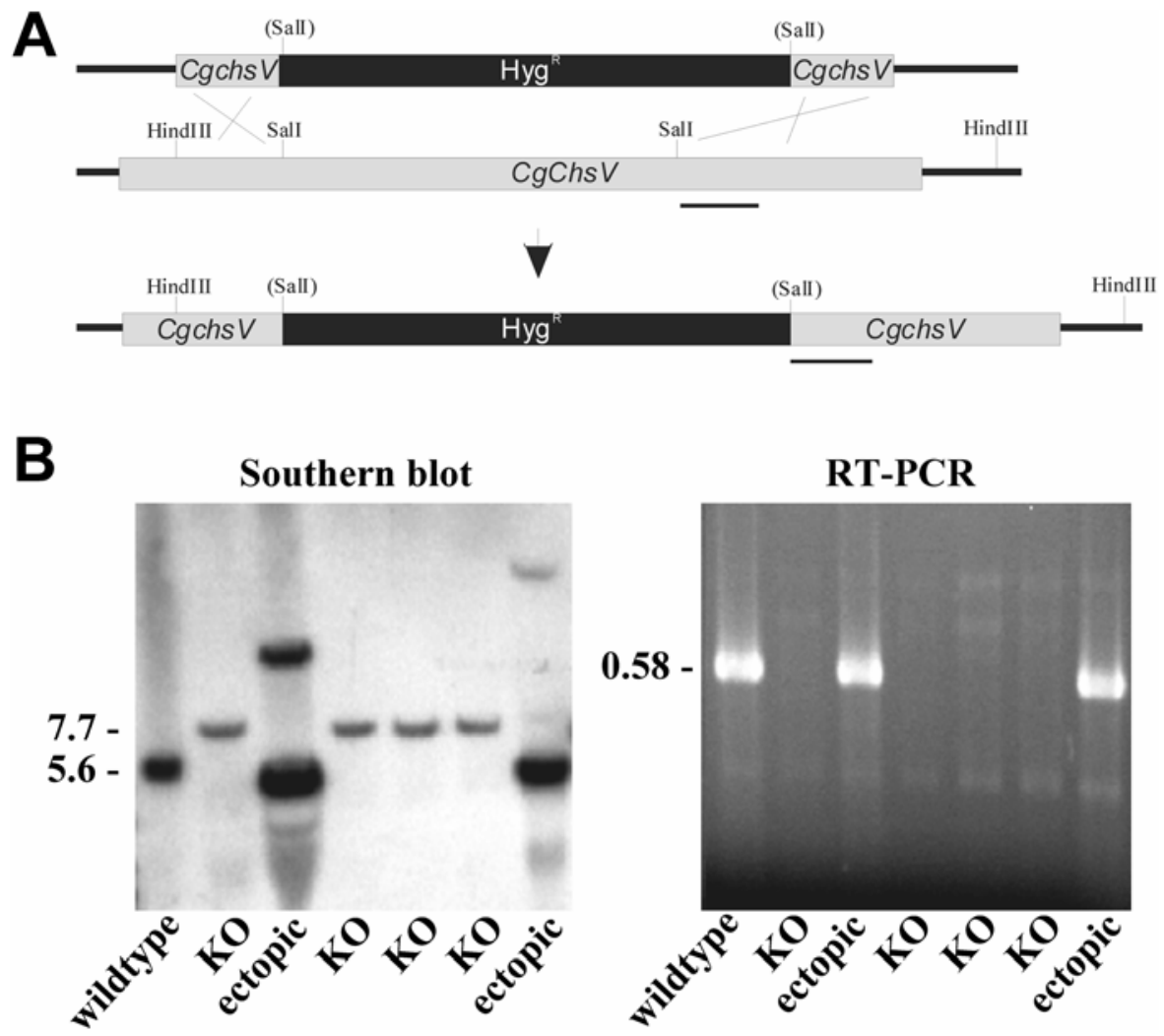

Fig. 4. Targeted inactivation of the $C g C h s V$ gene of Colletotrichum graminicola. A, Strategy of inactivation of the $C g C h s V$ gene by homologous recombination. In the $C g C h s V$ knock-out (KO) vector, a 3,021-bp SalI fragment was replaced by the hygromycin resistance cassette, and this construct was transformed into the $C$. graminicola wild-type strain CgM2. Bars indicate probe used in Southern blot experiments. B, Southern blot of DNA isolated from $C$. graminicola wild type and transformants with homologous $(\mathrm{KO})$ and ectopic integration (ectopic) of the KO vector. In reverse-transcription polymerase chain reaction (RT-PCR) analyses, products only occurred in the wild-type strain and in C. graminicola strains with ectopic integration of the KO vector (compare Southern blot and RT-PCR). Fragment sizes are given in kilobases. 
(Fig. 6C) and some of these cells were attached to the polyester substratum (not shown). Very occasionally, the formation of an appressorial initial was observed (Fig. 6D, arrowhead); however, during enlargement and maturation of these cells, the appressorial wall was unable to maintain the appressorial shape. These data suggest that $\mathrm{CgChsV}$ has essential roles in appressorium differentiation.

C. graminicola can also invade the host plant by forming infection structures called hyphopodia. These are lobed melanized infection cells formed by vegetative hyphae (Fig. 6E, arrow), which are thought to functionally resemble appressoria. Surprisingly, the $\triangle C g C h s V$ mutant differentiated melanized domeshaped hyphopodia of a size comparable with that of wild-type hyphopodia (Fig. 6F, arrow). However, occasionally large and swollen melanized hyphopodia were found (Fig. 6G, arrow). In hyphopodia, no cell wall distortions comparable with those in appressorial walls were found (Fig. 6G, compare hyphopodium indicated by arrow and disintegrated appressorium indicated by arrowhead). Thus, $\mathrm{CgChsV}$ participates in the formation of hyphopodia but, in contrast to the role of this enzyme in appressoria, it is not essential for hyphopodium differentiation. Next, we tested whether hyphopodia of $\Delta C g C h s V$ mutants were able to exert force in order to invade the host epidermis. Surprisingly, quantitative measurements by optical waveguides revealed that force exerted by wild-type and $\Delta C g C h s V$ hyphopodia did not differ significantly (Fig. 6D). Moreover, force generated by hyphopodia was comparable with that exerted by wild-type appressoria (Bechinger et al. 1999).

\section{CgChsV is essential for hyphal growth in planta.}

$\Delta C g C h s V$ null mutants were able to differentiate hyphopodia, suggesting that they are able to infect plants. To investigate the role of $C g C h s V$ in pathogenic development, infection assays were performed with the $\Delta C g C h s V$ mutant and wild-type strains (Fig. 7). Microscopical analyses of infection by wildtype cells showed that hyphopodia (Fig. 7A, asterisk) invaded the host leaf to form thick, primary hyphae (Fig. 7A, large arrowhead) from which thin, destructive secondary hyphae (Fig. 7A, small arrowhead) grew out to colonize the host tissue. Thus, infection hyphae initiating from hyphopodia closely resemble those developing from appressoria. Consistent with the in vitro studies described above, both wild-type and $\Delta C g C h s V$ mutants formed hyphopodia on the plant surface when osmolytically stabilized (Fig. 7A; black bars), and post-penetration infection structures formed at comparable rates (Fig. 7B: gray bars, infection vesicles; hatched bars, primary hyphae; white bars, secondary hyphae). However, the infection hyphae formed by $\Delta C g C h s V$ mutants within the first host cell showed large swellings (Fig. 7A, arrows). These hyphae were able to penetrate host cell walls to grow into neighboring cells, but the ability to colonize the host tissue was severely reduced.

Consequently, when the inoculum was applied to host leaves in the presence of osmolytes, the $\Delta C g C h s V$ mutant did not cause any disease symptoms, whereas wild-type and transformants with ectopically integrated $\mathrm{KO}$ vector were able to cause anthracnose lesions on wounded and unwounded leaves (Fig. 7C).

These results show that $\mathrm{CgChsV}$ is required for post-penetration pathogenic development of $C$. graminicola. In the absence of osmotic stabilization, however, the $\triangle C g C h s V$ mutant was unable to differentiate hyphopodia on the maize leaf surface (Fig. 7B) and, therefore, infections did not occur under these conditions.

In order to test whether the pathogenicity defect of $\Delta C g C h s V$ mutants also was due to increased sensitivity to plant defense
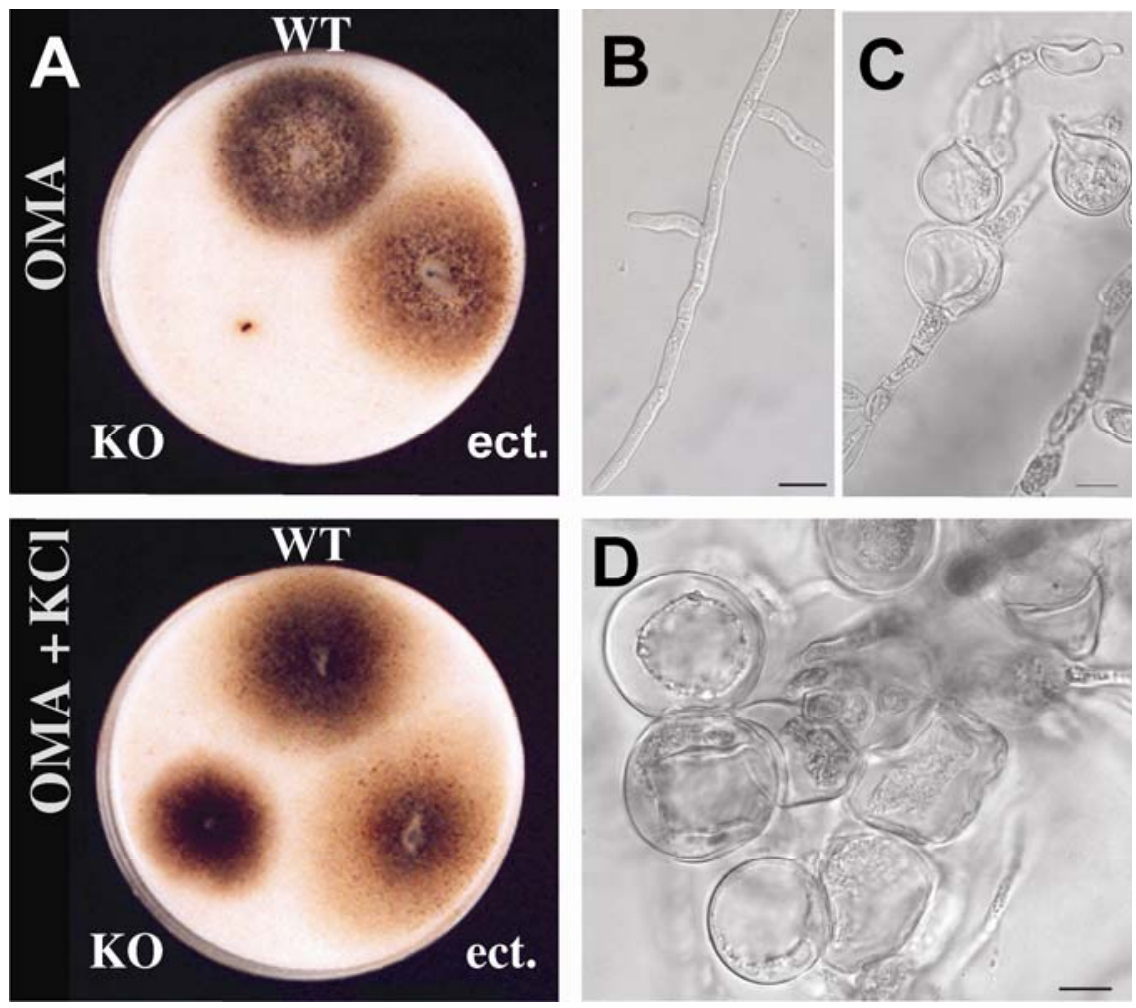

Fig. 5. Vegetative growth and hyphal morphology of Colletotrichum graminicola wild type (WT), a $\Delta C g C h s V$ mutant strain, and a strain with ectopic integration of the knock-out (KO) vector. A, Vegetative growth on agar plates. On oatmeal agar (OMA) plates, the WT strain and the strain with ectopic integration of the KO vector grew to form colonies. The $\triangle C g C h s V$ mutant strain was not able to grow. On osmotically stabilized plates (OMA + KCL), the $\Delta C g C h s V$ mutant strain was able to grow and showed only slightly reduced growth rates compared with the WT strain and the strain with ectopic integration of the KO vector. $\mathbf{B}$ through $\mathbf{D}$, Micrographs of vegetative hyphae of $\mathbf{B}$, the WT strain CgM2 and $\mathbf{C}$ and $\mathbf{D}$, the $\Delta C g C h s V$ mutant strain in liquid complete medium supplemented with $0.5 \mathrm{M}$ sucrose. In spite of osmotic stabilization, $\Delta C g C h s V$ hyphae showed $\mathbf{C}$, balloon-like protrusions occurring occasionally along filaments or $\mathbf{D}$, large numbers of closely associated swellings. Bars represent $10 \mu \mathrm{m}$. 
compounds such as $\mathrm{H}_{2} \mathrm{O}_{2}$, growth assays were performed on $\mathrm{CM}$ amended with $0.5 \mathrm{M}$ sucrose and approximately $0.01 \%$ (vol/vol) $\mathrm{H}_{2} \mathrm{O}_{2}$. At 4 days postinoculation, growth of the wildtype strain was inhibited by $88.5 \pm 2.4 \%$. For comparison, growth inhibition measured for $\triangle \mathrm{CgChsV}$ and for ectopic transformants were $83.6 \pm 15.0 \%$ and $87.3 \pm 2.3 \%$, respectively (data not shown). Differences in inhibition were not statistically different $(P=0.05)$. Although these data indicate that pathogenicity defects are primarily due to cell wall defects rather than increased sensitivity to $\mathrm{H}_{2} \mathrm{O}_{2}$ (Madrid et al. 2003), it should be noted that vegetative hyphae analyzed in growth assays cannot directly be compared with infection hyphae.

\section{DISCUSSION}

Chemically, the fungal cell wall consists of 80 to $90 \%$ polysaccharides (Bartnicki-Garcia 1968), and the gross monomeric composition of an average ascomycete cell wall shows a predominance of glucose and amino sugars, predominantly $\mathrm{N}$ acetylglucosamine (Sietsma and Wessels 1994). Chitin may contribute more than $50 \%$ of the dry weight of the cell wall (Aronson and Machlis 1959) and is thought to be essential for fungal cell wall rigidity. In several filamentous fungi, newly synthesized chitin localizes to the hyphal tip (Weber et al. 2006; Wessels 1993) and, by WGA labeling, we demonstrated that this also holds true for $C$. graminicola (Fig. 1). Strongly stained hyphal tips suggest that chitin is a prominent polymer in this fungus. The fact that only hyphal tips but not older, subapical regions expose chitin at the surface may be due to enzymatic modification of chitin that could be mediated by secreted chitin deacetylases (El Gueddari et al. 2002). Alterna- tively, lack of hyphal decoration by WGA could be due to apposition of other cell wall layers such as hydrophobin coatings (Wösten et al. 1994). Some hyphal tips of $C$. graminicola were not labeled by WGA, suggesting either that these hyphae were not actively growing or that the entire hyphal surface may have been modified (Sietsma and Wessels 1994), rendering them inaccessible for the lectin.

Studies involving CHS inhibitors, namely nikkomycins and polyoxins, demonstrated the importance of these enzymes and the polymers they synthesize for cell wall rigidity and form and function of fungal cell walls (Cabib et al. 1996). In contrast to yeasts, large numbers of CHS genes have been found in the genomes of filamentous fungi (Munro and Gow 2001) and, although inhibitor studies allow the determination of the importance of chitin synthesis (Zhang et al. 2000), they do not lead to an understanding of the role of individual CHS genes or enzymes. Targeted gene inactivation experiments made it possible to genetically dissect chitin synthesis and to investigate the one or more roles of individual genes in plant (Madrid et al. 2003; Weber et al. 2006) and human-pathogenic fungi (Munro and Gow 2001).

We have cloned and functionally characterized a class I, a class III, and a class V CHS gene of the filamentous ascomycete and maize pathogen $C$. graminicola. This is the first report that a class V CHS with a myosin-like motor domain is indispensable for vegetative growth, differentiation of infection structures, and pathogenic development of this plant-pathogenic fungus.

\section{Structure of the $C$. graminicola CHS.}

Due to their high degree of conservation, class I to III CHS genes have been isolated with degenerate PCR primers (Bowen
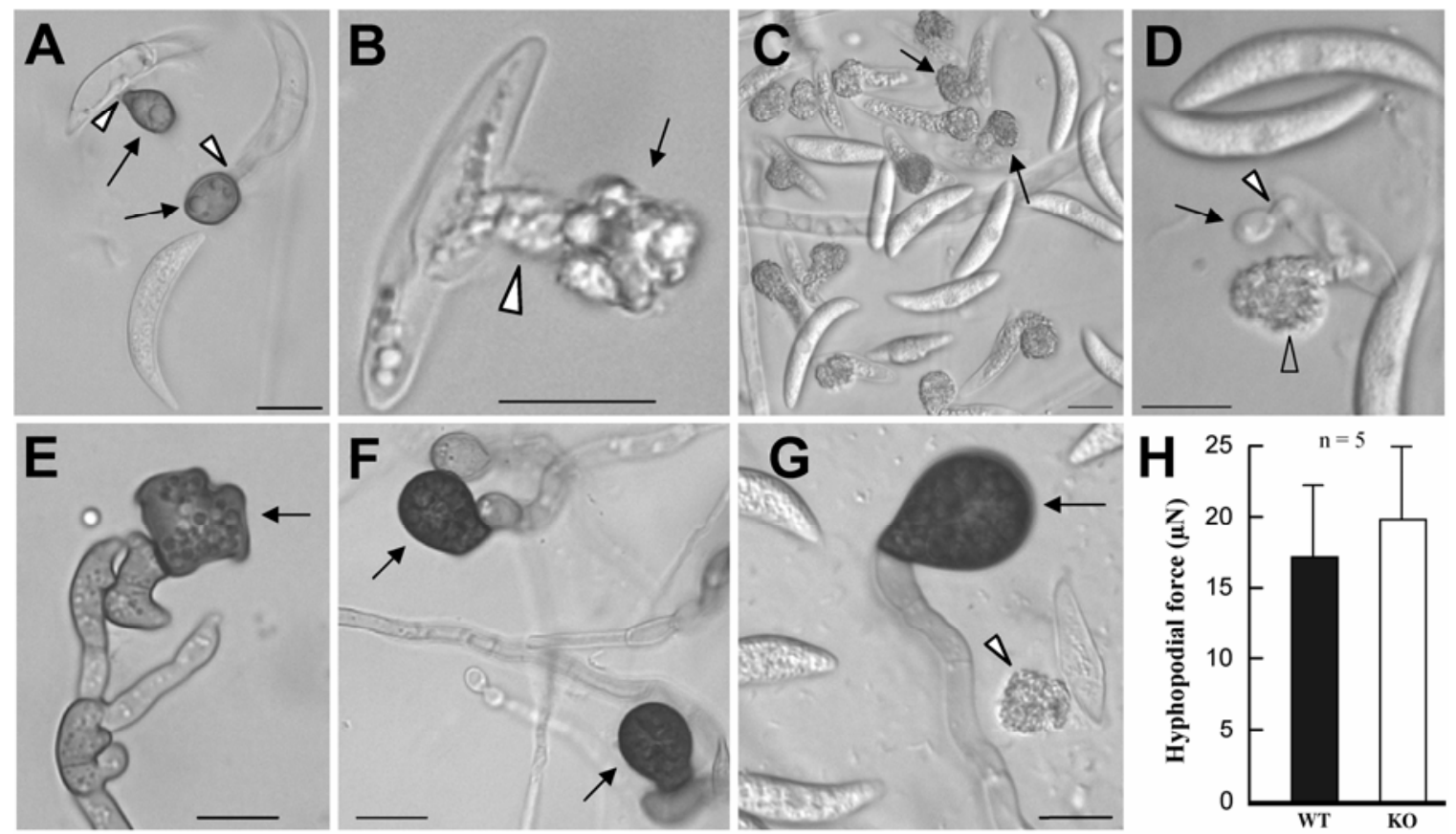

Fig. 6. Infection structure differentiation and hyphopodial force exertion by Colletotrichum graminicola wild type and the $\Delta C g C h s V$ mutant strain. Appressorium differentiation by $\mathbf{A}$, the wild-type strain $\mathrm{CgM} 2$ and $\mathbf{B}$ through $\mathbf{D}$, the $\Delta C g C h s V$ mutant strain. On a hard, hydrophobic surface, wild-type conidia germinate, form a short germ tube (A, arrowheads), and differentiate a melanized appressorium (A, arrows). Likewise, conidia of the $\Delta C g C h s V$ mutant form a germ tube (B, arrowhead) and an appressorium (B, arrow), but the infection cell is drastically distorted. All fully enlarged appressoria differentiated by $\Delta C g C h s V$ conidia show lyzed cell walls (C, arrows). Appressorial initials (D, arrow) develop from germ tubes (D, white arrowhead) but exhibit cell wall defects after maturation, as indicated by a second appressorium (D, black arrowhead) formed by the same conidium. Differentiation of hyphopodia by $\mathbf{E}$, the wild-type strain $\mathrm{CgM} 2$ and $\mathbf{F}$ and $\mathbf{G}$, the $\Delta C g C h s V$ mutant strain. Although the wild-type strain forms lobed, melanized hyphopodia (E, arrow), hyphopodia of the mutant also are melanized, but dome-shaped (F and G, arrows). Occasionally, larger, melanized swollen hyphopodia can be observed (G, arrow). Hyphopodia (G, arrow) do not exhibit cell wall defects comparable with those found in appressoria (G, arrowhead) developing in close vicinity. Infection cells were observed $48 \mathrm{~h}$ after inoculation of polyester sheets. Bars indicate $10 \mu \mathrm{m}$. H, Force measurement using optical waveguides. Force exerted by hyphopodia of the wild-type (WT) and $\Delta C g C h s V$ mutant strain (KO) were measured by optical waveguides. 
et al. 1992). The homologous region is restricted to approximately two-thirds of the carboxyl terminus and, in most cases, hydrophobic membrane-spanning domains are found near this end (Cabib et al. 1996). Although these features have been established with the yeast $S$. cerevisiae, they also hold true for other fungi (Weber et al. 2006). In C. graminicola, class I and III CHS exhibit eight hydrophobic membrane-spanning domains at their carboxyl ends and, thus, are typical examples of these enzyme classes. Whether or not they are zymogenic like other class I to III CHS (Mellado et al. 2003) has not been determined.

Class IV to VI CHS genes have been isolated either using PCR primers based on the ScCHS3 sequence, with primers specifically designed to amplify fragments of CHS with a myosin-like motor domain, or by random insertional mutagenesis (Amnuaykanjanasin and Epstein 2003; Madrid et al. 2003; Munro and Gow 2001). In contrast to class IV CHS, enzymes classified as class V CHS have a myosin-like motor domain with significant similarity to the consensus sequence of singleheaded myosins, including a classical ATP-binding motifs (Ploop and switch I and II motifs) and the IQ motif. The myosin motor of some CHS (e.g., Chs4 of Paracoccioides brasiliensis, AoChsZ of A. oryzae, and UmChs6 of $U$. maydis) are somewhat degraded and, thus, distinct from class V CHS. Nino-
Vega and associates (2004) proposed that these CHS should be classified as a new class of enzymes, and enzymes with a shorter myosin-like binding domain lacking classical ATPbinding motifs or the IQ motif have now been designated as class VI CHS (Mellado et al. 2003; Munro and Gow 2001; Takeshita et al. 2006). In C. graminicola, typical class V (this study) and VI (Amnuaykanjanasin and Epstein 2003) CHS exist, each consisting of approximately 1,800 amino acids and exhibiting six transmembrane domains and either a complete or a shorter myosin-like motor domain (Fig. 3).

\section{Filamentous growth requires a class $\mathrm{V}$ CHS with a myosin-like motor domain.}

Class III, V, and VI CHS have been identified only in filamentous and some dimorphic fungi that are able to differentiate true hyphae. Individual replacement mutagenesis of the class I and III genes $C g C h s I$ and $C g C h s I I I$ of $C$. graminicola did not cause alterations in hyphal development or conidiation. This may not necessarily be due to lack of function in filamentous growth but, rather, could be due to overlaps in gene and enzyme function. Also, in A. fumigatus, deletion of the class I, II, and IV CHS genes $A f c h s A, A f c h s B$, and $A f c h s F$ had little effect on morphology and growth (Munro and Gow 2001). A class III CHS was not important in the dimorphic basidiomy-

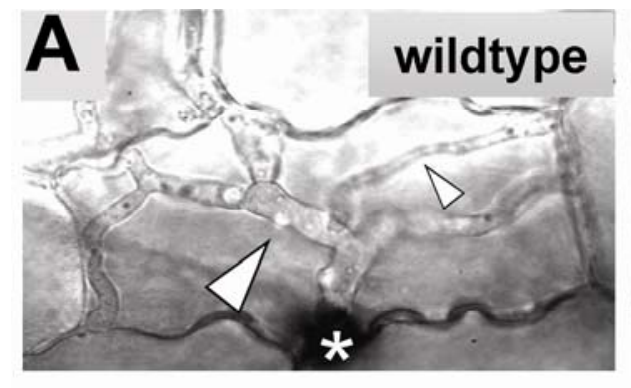

B

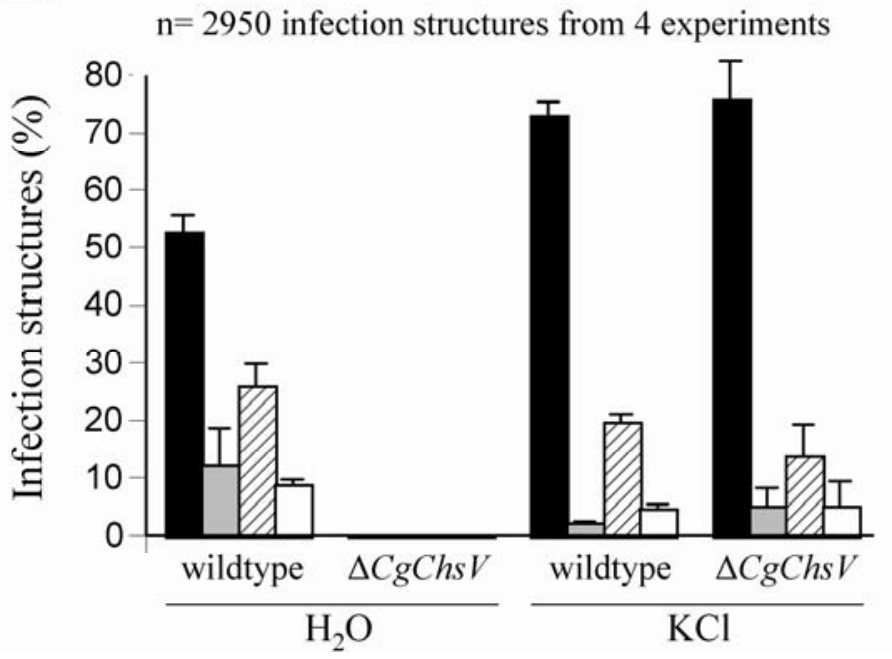

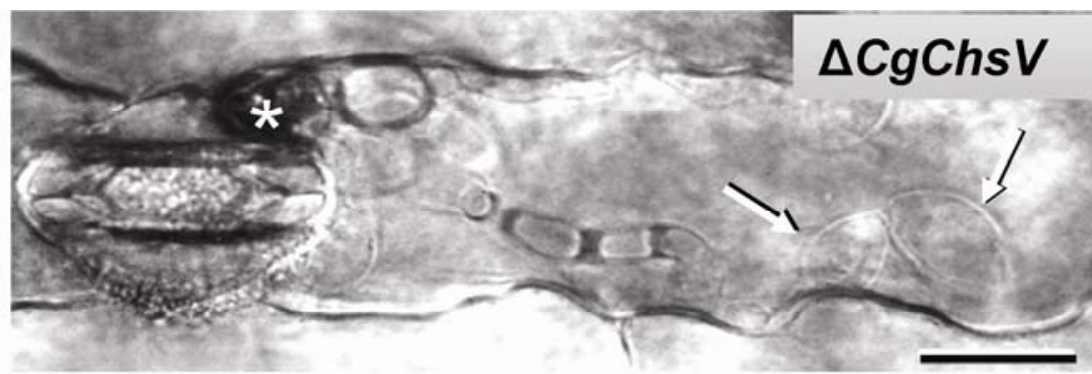
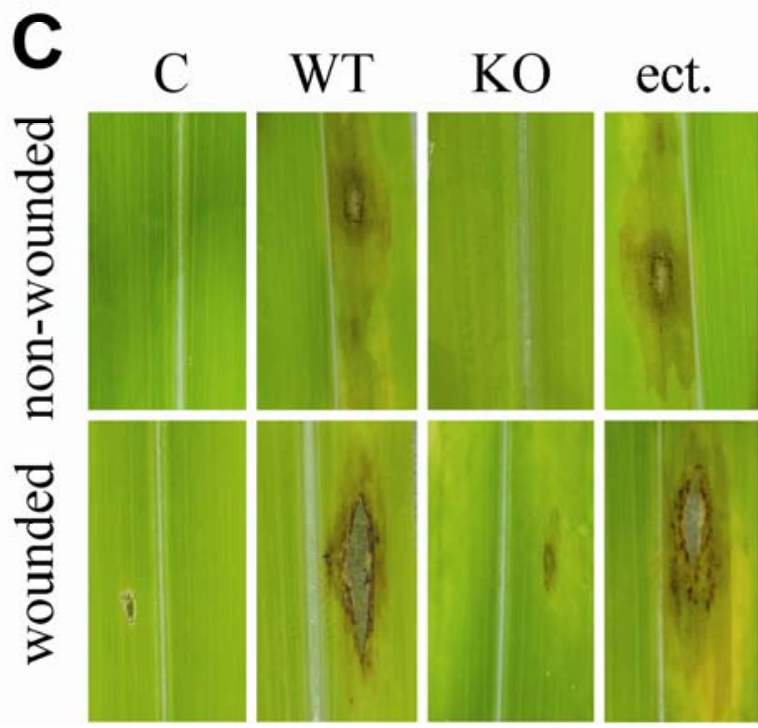

Fig. 7. Penetration competence and pathogenicity of Colletotrichum graminicola wild-type strain, $\Delta C g C h s V$ mutant strain, and a strain with ectopic integration of the knock-out (KO) vector. A, Microscopical analysis of the penetration process. Wild-type and $\Delta C g C h s V$ hyphopodia (asterisks) formed in the presence of $0.5 \mathrm{M}$ sucrose and invaded the host epidermal cell. The wild type formed thick primary hyphae (large arrowhead) and thin secondary hyphae (small arrowhead). Intracellular hyphae of the $\Delta C g C h s V$ mutant showed balloon-like swellings (arrows) and grew more slowly than corresponding wild-type hyphae. B, Osmolyte effect on infection structure differentiation by wild-type and $\Delta C g C h s V$ mutant on maize leaves. In the absence of the osmolyte, the $\Delta C g C h s V$ mutant is unable either to grow and form hyphopodia on the leaf surface or to differentiate infection structures in planta. In the presence of 150 $\mathrm{mM} \mathrm{KCl}$, rates of infection structure differentiation are comparable. Black bars, hyphopodia; gray bars, infection vesicles; hatched bars, primary hyphae; white bars, secondary hyphae. Error bars indicate standard deviation. Infection structure formation was scored $48 \mathrm{~h}$ postinoculation. C, Leaf infection assays. Mycelia of the wild type (WT), a $\Delta C g C h s V$ mutant strain, and a strain with ectopic integration of the KO vector were placed onto the surface of intact or wounded maize leaves. Infection droplets contained $0.5 \mathrm{M}$ sucrose. Regardless of wounding, anthracnose symptoms developed after inoculation with the WT strain and a strain with ectopic integration of the KO vector. The $\Delta C g C h s V$ mutant strain (KO) did not cause disease on either intact or wounded leaves. Noninoculated control leaves (C) also are shown. Photographs were taken 6 days postinoculation. 
cete U. maydis (Gold and Kronstad 1994; Weber et al. 2006) and class III CHS do not even exist in Phycomyces blakesleeanus (Miyazaki and Ootaki 1997). In contrast, mutants of the gray mold fungus $B$. cinerea deficient in the class III CHS BcChs3a were severely impaired in growth on solid substratum (Soulié et al. 2006). In U. maydis, two class IV CHS, Chs5 and Chs7, have been shown to be essential for fungal morphogenesis and filamentous growth (Weber et al. 2006), and class IV CHS also have important roles in hyphal growth of the dimorphic fungus $C$. albicans (Mio et al. 1996) and in the yeast $S$. cerevisiae (Shaw et al. 1991). However, in the filamentous fungus $N$. crassa, deletion of class IV CHS was without significant effect (Beth Din et al. 1996). These findings raised doubts about specific cellular functions of individual classes of CHS, and the situation is even more complicated by the fact that CHS of different classes cooperate to mediate hyphal growth and conidiation (Fujiwara et al. 2000; Motoyama et al. 1997).

A growing body of literature shows that mutations in individual class $\mathrm{V}$ and VI genes drastically affect filamentous growth. C. graminicola $\triangle \mathrm{CgChsV}$ replacement mutants showed swollen hyphal tips and balloon-like structures along the hyphae, similar to those seen in A. nidulans mutants deficient in the class V CHS gene $\operatorname{csmA}$ (Horiuchi et al. 1999). In F. oxysporum class V CHS mutants, occurrence of balloon-like structures was suppressed in solid synthetic media complemented with osmotic stabilizers, indicating that swellings result from cell wall weakening and, in turn, that class V CHS play a major role in maintenance of hyphal wall integrity and polarized cell wall synthesis (Madrid et al. 2003). As indicated by the inability of $C$. graminicola $\Delta C g C h s V$ mutants to form conidia on the surface of solid substrata, the class V CHS also plays a role in asexual sporulation. This also has been observed in $\triangle$ csmA mutants of $A$. nidulans. In addition to cell wall weakening, inactivation of the $\operatorname{csm} A$ gene led to formation of hyphae within previously formed older hyphae (intrahyphal growth) (Horiuchi et al. 1999).

Mutating the A. nidulans class VI CHS gene $\operatorname{csm} B$ caused formation of balloons, intrahyphal hyphae, lysis in subapical hyphal regions, and drastically reduced conidiation; thus, $\operatorname{csm} A$ and $\operatorname{csm} B$ mutants show a similar phenotype. Staining experiments indicated that CsmA and CsmB co-localized with actin, but immuno-precipitation experiments did not suggest a physical interaction between these enzymes (Takeshita et al. 2006). In $C$. graminicola, inactivation of the class VI CHS gene caused conidial bursting and swelling of hyphal tips in media with low osmotic pressure, indicating the role of this enzyme in cell wall strength of conidial and vegetative hyphae (Amnuaykanjanasin and Epstein 2003). These data suggest that filamentous growth in several fungi, including $C$. graminicola, requires class $\mathrm{V}$ or class VI CHS with a myosin-like motor domain.

\section{Role of chitin synthases in pathogenesis.}

Apical growth is a hallmark of filamentous fungi, allowing invasion and colonization of solid substrata, including living tissues of either plant or animal origin (Wessels 1993). Fungal pathogenesis requires invasive growth (Deising et al. 2000; Stoldt et al. 1997); therefore, one may expect that CHS exclusively found in filamentous fungi are required for pathogenicity or virulence. Functional characterization of enzymes such as chitin and $\beta-1,3$-glucan synthases is essential not only to understand fungal pathogenicity but also to identify novel fungicide targets to be used in agriculture and medicine (Debono and Gordee 1994; Georgopapadakou 2001).

In comparison with information on the role of chitin synthases in vegetative development, little is known about the role of chitin synthesis and CHS during pathogenic growth. CHS with myosin motor domains have been found in filamentous fungi, including plant pathogens such as F. oxysporum (Madrid et al. 2003), B. cinerea (Choquer et al. 2004), Magnaporthe grisea (Vidal-Cros and Boccara 1998), and U. maydis (Weber et al. 2006), and also in human pathogens such as A. fumigatus (Aufauvre-Brown et al. 1997), Paracoccidioides brasiliensis (Nino-Vega et al. 2004), and Wangiella dermatitides (Liu et al. 2004). The $m c s 1$ gene of $U$. maydis is specifically required for invasive growth in planta. However, the class VI CHS of the corn smut fungus $U$. maydis, Chs6, also contributes to fungal pathogenicity (Garcera-Teruel et al. 2004; Weber et al. 2006). Likewise, targeted chs $V$ replacement mutants of $F$. oxysporum failed to colonize the vascular system of tomato plants and to invade wounded tomato fruit (Madrid et al. 2003).

In contrast to $U$. maydis and $F$. oxysporum, the corn anthracnose fungus $C$. graminicola differentiates distinct appressoria. These infection cells are melanized and previous studies have shown that they exert significant force to invade an epidermal host cell (Bechinger et al. 1999). Because nonmelanized mutants are unable to infect corn (Rasmussen and Hanau 1989), generation of turgor and its translation into force are thought to be essential for pathogenesis. On polyester sheets, $\triangle \mathrm{CgChsV}$ mutants formed germ tubes and appressorial initials, but failed to differentiate functional (i.e., plant cell wall-penetrating) appressoria (Fig. 6). These data clearly indicate that $C g C h s V$ is indispensable for synthesis of rigid appressorial cell walls and for appressorium-mediated plant infection. Surprisingly, $\triangle \mathrm{CgChsV}$ mutants were able to synthesize hyphopodia, which exhibited a distinct morphology, but exerted force and penetrated the host epidermis at rates comparable with wild-type hyphopodia (Figs. 6 and 7), allowing the study of infection structure formation in planta. After entering the epidermal host cell, C. graminicola $\Delta C g C h s V$ primary hyphae swell markedly, reminiscent of the phenotype of the infection hyphae of $U$. maydis $\Delta m c s 1$ mutants (Weber et al. 2006), and anthracnose disease symptoms did not develop. Thus, the class $\mathrm{V}$ chitin synthase $\mathrm{CgChsV}$ of $C$. graminicola is essential for both pre- and post-invasive stages of plant infection. Class V mutants of neither $C$. graminicola nor $U$. maydis exhibit increased sensitivity toward $\mathrm{H}_{2} \mathrm{O}_{2}$, suggesting that reduced virulence is due to cell wall defects per se, rather than to increased sensitivity to plant defense compounds (Weber et al. 2006; this study). Thus, increased sensitivity to reactive oxygen species may be specific for the class $\mathrm{V}$ chitin synthase mutant of $F$. oxysporum (Madrid et al. 2003).

Class V CHS of the plant pathogens $C$. graminicola, $U$. maydis, and $F$. oxysporum, as well as of the black fungal pathogen of humans, $W$. dermatitidis contribute to virulence (Liu et al. 2004; Madrid et al. 2003; Weber et al. 2006; this study); therefore, it would be tempting to investigate the role of these enzymes in a broader spectrum of pathogenic fungi. It is important to note, however, that pathogenicity assays in plants and animal models are difficult to compare, as indicated by studies with the tomato pathogen $F$. oxysporum. chs $V$ mutants of this fungus are nonpathogenic on plants but show increased virulence in immunodepressed mice (Ortoneda et al. 2004).

Our study has shown that a class V CHS is a viability and pathogenicity factor in the maize anthracnose fungus $C$. graminicola and suggests that this class of fungal CHS may be important for infection of plants. Although general conclusions cannot be drawn so far, increasing evidence suggests that class $\mathrm{V}$ CHS have important roles in fungal pathogenicity (Madrid et al. 2003; Weber et al. 2006), and one may speculate that these enzymes could represent excellent novel fungicide targets. Entire fungicide classes have been lost due to development of fungicide resistance in fungal pathogen populations; therefore, appropriate fungicide mixtures may not durably be available in 
agriculture, and the search for new fungicides will become increasingly important (Deising et al. 2002).

\section{MATERIALS AND METHODS}

\section{Fungal cultures and in vitro differentiation of infection structures.}

C. graminicola (Ces.) G. W. Wilson (teleomorph Glomerella graminicola D. J. Politis) strain M2 was kindly provided by R. L. Nicholson, Purdue University, IN, and used as wild-type strain in this study. The wild-type strain and $\Delta C g C h s I$ and $\Delta C g C h s I I I$ mutants were grown on OMA (50 g of blended oatmeal [Haferflocken Großblatt aus ökologischem Anbau, Bohlsener Mühle, Bohlsen, Germany] and $12 \mathrm{~g}$ of agar-agar [Difco Laboratories, Augsburg, Germany] per liter) at $23^{\circ} \mathrm{C}$ under continuous fluorescent light (Climas Control CIR, UniEquip, Martiensried, Germany). Alternatively, strains were grown in CM (Leach et al. 1982) in an incubation shaker (Unitron, Infors AG, Bottmingen, Switzerland) at $110 \mathrm{rpm}$ and $23^{\circ} \mathrm{C}$. To solidify CM, $1.5 \%$ (wt/vol) agar-agar (Difco Laboratories) was added. $\Delta C g c h s V$ mutants were kept on oatmeal or $\mathrm{CM}$ agar plates or in $\mathrm{CM}$ liquid medium supplemented with $0.15 \mathrm{M} \mathrm{KCl}, 1 \mathrm{M}$ sorbitol, or $0.5 \mathrm{M}$ sucrose.

To determine $\mathrm{H}_{2} \mathrm{O}_{2}$ sensitivity, strains were grown on solidified CM containing $0.5 \mathrm{M}$ sucrose and approximately $0.01 \%$ (vol/vol) $\mathrm{H}_{2} \mathrm{O}_{2}$. Plates without $\mathrm{H}_{2} \mathrm{O}_{2}$ served as controls.

To induce differentiation of infection structures in vitro, aqueous spore suspensions were adjusted to a concentration of $10^{4}$ conidia/ml, and 10 - to $20-\mu 1$ droplets were inoculated onto polyester transparency sheets (no. 3558; Avery Dennison Zweckform, Holzkirchen, Germany) and incubated at $100 \%$ relative humidity at $23^{\circ} \mathrm{C}$. Alternatively, mycelial fragments were placed onto polyester sheets and incubated in droplets of $\mathrm{CM}$ liquid medium supplemented with $0.5 \mathrm{M}$ sucrose and incubated at $100 \%$ relative humidity at $23^{\circ} \mathrm{C}$. Under these conditions, hyphopodia and phialides forming new conidia occurred. These conidia germinated to differentiate appressoria. Formation of infection structures was evaluated 24 or $48 \mathrm{~h}$ after inoculation of membranes.

\section{Plant material and infection assay.}

Maize (Zea mays cv. Mutin) plants were grown in a greenhouse with an approximately $16-\mathrm{h}$ photoperiod at 20 to $26^{\circ} \mathrm{C}$. Infection assays in the presence of the CHS inhibitor nikkomy$\operatorname{cin} \mathrm{Z}$ were done with the youngest fully expanded detached leaf of 2- to 3-week-old plants. The conidial density was adjusted to $5 \times 10^{5} / \mathrm{ml}$ in diluted potato dextrose broth (48 $\mathrm{mg} / \mathrm{liter}$ ) (Difco Laboratories) and 10- $\mu$ l droplets were placed onto the adaxial leaf surface. Alternatively, because $\Delta C g C h s V$ mutants failed to produce functional appressoria, inoculation was carried out with mycelial fragments (approximately 1 $\mathrm{mm}^{2}$ ) taken from the edge of a colony growing on OMA. The mycelia were suspended in liquid CM supplemented with 0.5 $M$ sucrose and placed onto the adaxial leaf surface. Under these conditions, hyphae differentiated hyphopodia on the leaf surface. To discriminate between penetration capacity and the ability to grow within corn leaf tissue, leaves that had been injured with a sterilized needle also were inoculated.

Leaves were placed into a humid chamber $(100 \%$ relative humidity) and kept at $22^{\circ} \mathrm{C}$ with a 16-h light period (photon flux $<300 \mu \mathrm{mol} / \mathrm{m}^{2} / \mathrm{s}$ ) in a growth chamber (Percival I-36HIL; Percival Manufacturing Company, Boone, IA, U.S.A.).

\section{Cloning of chitin synthase genes and sequence analyses.}

Genomic DNA was isolated from the C. graminicola wildtype strain CgM2 using the method described by Döbbeling and associates (1997). To amplify class I to III chitin synthase fragments, PCR reactions were performed with degenerate primers CHS1 (5'-CTG AAG CTT CAN ATG TAY AAY GAR GAY-3') and CHS2 (5'-GTT CTC GAG YTT RTA YTC RAA RTT YTG-3') as designed by Bowen and associates (1992). To amplify DNA fragments of class IV to VI chitin synthases, primers CHS3 (5'-AAR CCI GGI AAY MGR GGI AAR MG$3^{\prime}$ ) and CHS4 (5'-GTT RTG IAC IGT IGA RTT DAT CC-3') were designed. Reaction mixtures $(10$ to $20 \mu \mathrm{l})$ contained genomic DNA (10 ng), primers $(0.5 \mu \mathrm{M}$ each), $0.02 \mathrm{U}$ of Taq polymerase/ $\mu \mathrm{l}$ (Qiagen, Hilden, Germany), $0.2 \mathrm{mM}$ dNTP each, and $1.5 \mathrm{mM} \mathrm{MgCl} 2$ in reaction buffer. The PCR program included initial denaturation $\left(5 \mathrm{~min}\right.$ at $\left.95^{\circ} \mathrm{C}\right) ; 30$ cycles of $20 \mathrm{~s}$ of denaturation at $94^{\circ} \mathrm{C}, 30 \mathrm{~s}$ of annealing at $60^{\circ} \mathrm{C}$, and $60 \mathrm{~s}$ of chain elongation at $72^{\circ} \mathrm{C}$; and a final elongation for $5 \mathrm{~min}$ at $72^{\circ} \mathrm{C}$. Fragments of $619,638,660$, and 710 bp were Klenow treated and cloned into SmaI-digested pTZ19R.

The PCR fragments were digoxigenin (DIG) labeled by PCR with a dNTP mix containing DIG-dUTP and used to screen a genomic DNA library, as recommended by the manufacturer (PCR DIG Probe Synthesis Kit; Roche Diagnostics, Mannheim, Germany). The cosmid library of $C$. graminicola was constructed in the cosmid vector pSV50 (Vollmer and Yanofsky 1986) and kindly provided by J. A. Rollins and R. M. Hanau, Purdue University, West Lafayette, IN, U.S.A. Cosmid clones containing the entire gene corresponding to the 660-bp fragment have not been found, and inverse PCR (Pang and Knecht 1997) with Mph1103I- and HindIII-digested genomic DNA were performed to cover the complete coding region.

DNA sequencing was done on an ABI Prism 310 automatic sequencer using BigDye Chemistry (Applied Biosystems; Weiterstadt, Germany), following the manufacturer's instructions. Sequence analyses were performed using the software supplied by ABI and the DNAStar programs (DNASTAR Inc., Madison, WI, U.S.A.). BLAST search was carried out on the National Center for Biotechnology Information server.

\section{Targeted gene disruption.}

To generate the $C g C h s I \mathrm{KO}$ vector, the $C g C h s I$ gene was digested with Cfr42I and BamHI, removing a 1,037-bp fragment of the coding region. After treatment with the Klenow fragment, the 2,395-bp SalI fragment of pUCATPH (Lu et al. 1994) carrying the hygromycin resistance cassette was inserted into $C g C h s I$ to replace the $C f r 42 \mathrm{I}-\mathrm{BamHI}$ fragment. A DNA fragment consisting of the hygromycin resistance cassette flanked by 1,000 bp of $C g C h s I$ at the $5^{\prime}$ end and $971 \mathrm{bp}$ at the $3^{\prime}$ end was amplified using the Expand Long-Template PCR system (Roche Diagnostics) and the primers CHSI1 (5'-GTC ACA AAC ATC AGA CAC CCG T-3') and CHSI4 (5'-CAC CAC GGT AGT AGT CCA TCT G-3'). The amplified fragment was transformed into $\mathrm{CgM} 2$ to generate $\Delta C g c h s I$ mutants.

The 2,691-bp Acc65I-NdeI fragment of pUCATPH carrying the hygromycin resistance cassette was ligated into the CgChsIII gene digested with the same enzymes, so that 1,093 bp of the coding region of this CHS gene was replaced. A 4.91-kbp fragment of this construct was amplified using the primers CHSIII1 (5'-ACC CAA CCT AGG TCT CCT TCC-3') and CHSIII7 (5'-TCT AGA CAG CAT GGT TGG AAT GG-3') and the Expand Long-Template PCR system (Roche Diagnostics). To generate $\Delta C$ gchsIII mutants, the amplified fragment was transformed into $\mathrm{CgM} 2$.

The $C g C h s V$ gene was digested with SalI, removing a 3,021-bp fragment, and pUCATPH was digested with HindIII. T4-DNA polymerase treatment was performed such that the $C g C h s V$ ends carried a T- and pUCATPH carried an A-overhang. Thus, after ligation, the KO vector contained $974 \mathrm{bp}$ of the $C g C h s V$ gene $5^{\prime}$ and 1,621 bp $3^{\prime}$ of the hygromycin resistance cassette. This construct was transformed into CgM2. 
Transformation of $C$. graminicola basically followed the protocol described by Epstein and associates (1998), with some modifications. SYE medium $(0.5 \mathrm{M}$ sucrose and $0.1 \%$ [wt/vol] yeast extract) was inoculated to contain $10^{6}$ falcate conidia/ml and incubated in an incubation shaker (Unitron, Infors AG, Bottmingen, Switzerland) at $23^{\circ} \mathrm{C}$ and $110 \mathrm{rpm}$ for 3 days. Cultures were filtered through two layers of cheesecloth and the filtrate containing oval conidia was centrifuged at $4,260 \times g$ at $4{ }^{\circ} \mathrm{C}$ for $10 \mathrm{~min}$. The conidia were resuspended in $10 \mathrm{ml}$ of a protoplasting solution containing lysing enzyme from Trichoderma harzianum at $20 \mathrm{mg} / \mathrm{ml}$ (Sigma, Deisenhofen, Germany) and $0.1 \%$ (vol/vol) $\beta$-mercaptoethanol in 0.7 $\mathrm{M} \mathrm{NaCl}$, and incubated at $30^{\circ} \mathrm{C}$ for $3 \mathrm{~h}$ with slight agitation. Formation of protoplasts was controlled microscopically. The protoplasts were sedimented by centrifugation $\left(800 \times g\right.$ at $4^{\circ} \mathrm{C}$ for $10 \mathrm{~min}$ ), washed in $10 \mathrm{ml}$ of SCT (1 M sorbitol; $50 \mathrm{mM}$

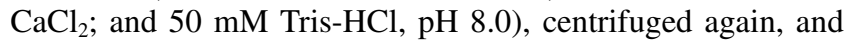
resuspended in $1 \mathrm{ml}$ of SCT. The KO vector $(0.5$ to $10 \mu \mathrm{g})$ was added to $100 \mu \mathrm{l}$ of the protoplast suspension and incubated on ice for $30 \mathrm{~min}$. After adding $1 \mathrm{ml}$ of PEG solution (40\% polyethylene glycol 4000; $0.6 \mathrm{M} \mathrm{KCl} ; 50 \mathrm{mM} \mathrm{CaCl}_{2}$; and $50 \mathrm{mM}$ Tris- $\mathrm{HCl}, \mathrm{pH} 8.0$ ) and incubation at room temperature for 20 min, 3 to $4 \mathrm{ml}$ of liquid regeneration medium (1 M sucrose, $0.1 \%$ [wt/vol] yeast extract, $0.1 \%$ [wt/vol] casein, and $0.6 \%$ [wt/vol] agar; $45^{\circ} \mathrm{C}$ ) was added and poured onto selection plates containing hygromycin B at $400 \mu \mathrm{g} / \mathrm{ml}$ and $1.5 \%$ (wt/vol) agar. After 7 to 10 days, growing colonies were transferred to new selection plates containing hygromycin B at 100 $\mu \mathrm{g} / \mathrm{ml}$. To obtain homokaryotic transformants, colonies that had developed on selection plates were allowed to conidiate on OMA. Conidia again were plated out on selection plates containing hygromycin B at $100 \mu \mathrm{g} / \mathrm{ml}$.

To identify transformants with homologous and ectopical integration of the $\mathrm{KO}$ vector, DNA was extracted and digested with BamHI (CgChsI), Acc65I plus XhoI (CgChsIII), or HindIII $(C g C h s V)$. After electrophoresis, DNA was blotted onto positively charged nylon membranes (Roche Diagnostics) by an alkaline downward procedure (Brown 1999), and hybridized with a DIG-labeled probe, as suggested by the manufacturer (DIG user's guide; Roche Diagnostics). Probes of $696 \mathrm{bp}$ (CgChsI), 780 bp (CgChsIII), and 560 bp (CgChsV) were amplified with primer combinations CHSIr1 andCHSI3 (5'-GCA GTT GGG CTG GTG AAA GG-3'); CHSIII6 (5'-GGT TCA GAC AAG ACT GAG GCG C-3') and CHSIII7; and CHSV2.1 (5'-CCT GCA CCA TTG CAC CCG AC-3') and CHSVr1 (5'AGC GAG CGT CCT CCT TGT TC-3'). Chemiluminiscence was visualized on Hyperfilm ECL (Amersham, Pharmacia, Freiburg, Germany) after adding CSPD (1\% [vol/vol] in detection buffer) (Roche Diagnostics).

RNA isolation and gene expression analyses.

Total RNA was isolated following the protocol of Chomczynski and Sacchi (1987).

RT-PCR was performed with the OneStep RT-PCR kit (Qiagen). The total volume of $10 \mu \mathrm{l}$ contained 115 to $230 \mathrm{ng}$ of RNA, $0.6 \mu \mathrm{M}$ each primer, $0.4 \mathrm{mM}$ dNTPs, and $0.4 \mu \mathrm{l}$ of the enzyme mix (Omniscript, Sensiscript reverse transcriptase, and HotStar Taq-polymerase) (Qiagen).

To exclude DNA contaminations, RNA was incubated with RNase-free DNase (Promega $\mathrm{GmbH}$, Mannheim, Germany). As an additional control, primers flanking an intron were used in RT-PCR analyses.

For $\mathrm{CgChsI}$, the primer combination CHSI4 (5'-CGC TAT CGG TAA CTT CTT CCT G-3') and RTI2.2 (5'-TTG AGA ATG TTG GTG TAT GTG GG-3') made possible the amplification of a 458-bp fragment with mitochondrial (m)RNA and a 506-bp fragment with DNA as template. For CgChsIII, the primers CHSIII1 and CHSIII3 (5'-TGA TTC TGT GAG ACT GTA TGC G-3') yielded a 308-bp fragment with mRNA and a 446-bp fragment with DNA as template. For $C g C h s V$, the primer pair CHSVko (5'-TCT CGC TCA ACA CAT ACA CTT C-3') and CHSV13 (5'-TTG TGC CCG CCA TCA GGT AGT A-3') made possible the amplification of a 465-bp fragment with mRNA and a 520-bp fragment with DNA as template. Alternatively, the primer pair CHSV3 (5'-TTA CGC GTG TCG ACG TCG CC-3') and CHSVRT2 (5'-CAA GCA GCT GAA GAA TTA CGC C-3') yielded a 585-bp fragment with an mRNA template. For $C g C h s V I$, the primer combination ChsVIRT1 (5'-CCG AGC TGT ACG AAT ATT TGA TG-3') and ChsVIRT2 (5'-GTG CCG CGG TTT GAC AGT AGG-3' made possible the amplification of a 461-bp fragment with mRNA and a 516-bp fragment with DNA as template.

Reverse transcription was done at $50^{\circ} \mathrm{C}$ for $30 \mathrm{~min}$, followed by a denaturation step at $95^{\circ} \mathrm{C}$ for $15 \mathrm{~min}$. Then, 25 to $35 \mathrm{cy}-$ cles, consisting of denaturation at $94^{\circ} \mathrm{C}$ for $20 \mathrm{~s}$, annealing at $57^{\circ} \mathrm{C}$ for $30 \mathrm{~s}$, and elongation at $72^{\circ} \mathrm{C}$ for $45 \mathrm{~s}$, were followed by final elongation at $72^{\circ} \mathrm{C}$ for $10 \mathrm{~min}$.

In order to confirm intron positions, cDNAs of the complete CHS genes were sequenced.

All primers used in this study were from MWG Biotech AG (Ebersberg, Germany).

\section{Inhibitor studies with nikkomycin $\mathbf{Z}$.}

Nikkomycin Z (Sigma) was added to conidial suspensions at different concentrations ( 0 to $500 \mu \mathrm{M})$ prior to inoculation of polyester transparency sheets or maize leaf segments as described above. In vitro differentiated infection structures were evaluated $24 \mathrm{~h}$ after inoculation of transparency sheets; symptoms developed on leaf segments were photographed 3 to 4 days postinoculation.

\section{Measurement of hyphopodial force exertion by optical waveguides.}

Force measurement was performed with optical waveguides as described previously (Bechinger et al. 1999). Because $\triangle C g C h s V$ mutants produced neither falcate conidia nor intact hyphae in the absence of osmolytes, pieces of mycelia (approximately $1 \mathrm{~mm}^{2}$ ) were placed onto optical waveguides in $0.5 \mathrm{M}$ sucrose. Under these conditions, both wild-type and $\Delta C g C h s V$ mutant differentiated hyphopodia, and force was measured $24 \mathrm{~h}$ after inoculation of the waveguides.

\section{Microscopy and chitin staining.}

Microscopy was done with either a Nikon Eclipse E600 microscope (Nikon, Düsseldorf, Germany) equipped with brightfield and differential interference contrast optics or a Zeiss Axioplan Imaging II microscope (Oberkochen, Germany) and standard rhodamine or FITC filters. Digital images were taken with a DS-5M (Nikon) or a CoolSNAP-HQ CCD camera (Photometrics, Tucson, AZ, U.S.A.) controlled by the imaging software MetaMorph (Universal Imaging, Downingtown, PA, U.S.A.). Image processing was done with the software package Lucia 4.61 (Nikon) and the imaging software MetaMorph. For staining of chitin, cells were grown overnight in CM liquid medium supplemented with $0.5 \mathrm{M}$ sucrose, fixed with $3 \%$ formaldehyde for $10 \mathrm{~min}$, and incubated with TRITC-labeled WGA following described protocols (Wedlich-Söldner et al. 2000).

\section{ACKNOWLEDGMENTS}

The financial support of the fungal cell wall biogenesis projects in $\mathrm{H}$. B. Deising's lab by the Deutsche Forschungsgemeinschaft (De 403/7-1) and by CAPES Brazil to J. A. Sugui is gratefully acknowledged. We thank C. 
Bechinger, University of Stuttgart, Germany, and M. Bastmeyer, University of Karlsruhe, Germany, for hyphopodial force measurement, and D. Jany and A. Beutel for excellent technical assistance.

\section{LITERATURE CITED}

Amnuaykanjanasin, A., and Epstein, L. 2003. A class V chitin synthase gene, chsA is essential for conidial and hyphal wall strength in the fungus Colletotrichum graminicola (Glomerella graminicola). Fungal Genet. Biol. 38:272-285.

Aronson, J. M., and Machlis, L. 1959. The chemical composition of the hyphal walls of the fungus Allomyces. Am. J. Bot. 46:292-330.

Aufauvre-Brown, A., Mellado, E., Gow, N. A. R., and Holden, D. W. 1997. Aspergillus fumigatus chsE: A gene related to CHS3 of Saccharomyces cerevisiae and important for hyphal growth and conidiophore development but not pathogenicity. Fungal Genet. Biol. 21:141-152.

Bartnicki-Garcia, S. 1968. Cell wall chemistry, morphogenesis, and taxonomy of fungi. Annu. Rev. Microbiol. 22:87-108.

Bastmeyer, M., Deising, H. B., and Bechinger, C. 2002. Force exertion in fungal infection. Annu. Rev. Biophys. Biomol. Struct. 31:321-341.

Bechinger, C., Giebel, K.-F., Schnell, M., Leiderer, P., Deising, H. B., and Bastmeyer, M. 1999. Optical measurements of invasive forces exerted by appressoria of a plant pathogenic fungus. Science 285:1896-1899.

Bergstrom, G. C., and Nicholson, R. L. 1999. The biology of corn anthracnose. Knowledge to exploit for improved management. Plant Dis. 83:596-608.

Beth Din, A., Specht, C. A., Robbins, P. W., and Yarden, O. 1996. chs-4, a class IV chitin synthase gene from Neurospora crassa. Mol. Gen. Genet. 250:214-222.

Bowen, A. R., Chen-Wu, J. L., Momany, M., Young, R., Szaniszlo, P. J., and Robbins, P. W. 1992. Classification of fungal chitin synthases. Proc. Natl. Acad. Sci. U.S.A. 89:519-523.

Brown, T. 1999. Southern blotting. Pages 2.9.1-2.9.15 in: Current Protocols in Molecular Biology. F. M. Ausubel, R. Brent, R. E. Kingston, D. D. Moore, J. G. Seidman, J. A. Smith, and K. Struhl, eds. John Wiley \& Sons, New York.

Cabib, E., Shaw, J. A., Mol, P. C., Bowers, B., and Choi, W.-J. 1996. Chitin biosynthesis and morphogenetic processes. Pages 243-267 in: The Mycota. III. Biochemistry and Molecular Biology. R. Brambl and G. A. Marzluf, eds. Springer-Verlag, Berlin, Heidelberg, New York.

Cabib, E., Roh, D. H., Schmidt, M., Crotti, L. B., and Varma, A. 2001. The yeast cell wall and septum as paradigms of cell growth and morphogenesis. J. Biol. Chem. 276:19679-19682.

Chomczynski, P., and Sacchi, N. 1987. Single-step method of RNA isolation by acid guanidinium thiocyanate-phenol-chloroform extraction. Anal. Biochem. 162:156-159.

Choquer, M., Boccara, M., Goncalves, I. R., Soulie, M. C., and VidalCros, A. 2004. Survey of the Botrytis cinerea chitin synthase multigenic family through the analysis of six euascomycetes genomes. Eur. J. Biochem. 271:2153-2164.

Debono, M., and Gordee, R. S. 1994. Antibiotics that inhibit fungal cell wall development. Annu. Rev. Microbiol. 48:471-497.

Deising, H. B., Werner, S., and Wernitz, M. 2000. The role of fungal appressoria in plant infection. Microbes Infect. 2:1631-1641.

Deising, H. B., Reimann, S., Peil, A., and Weber, W. E. 2002. Disease management of rusts and powdery mildews. Pages 243-269 in: The Mycota XI. Application in Agriculture. F. Kempken, ed. Springer, Berlin.

Döbbeling, U., Böni, R., Häffner, A., Dummer, R., and Burg, G. 1997. Method for simultaneous RNA and DNA isolation from biopsy material, culture cells, plants and bacteria. Biotechniques 22:88-90.

El Gueddari, N. E., Rauchhaus, U., Moerschbacher, B. M., and Deising, H. B. 2002. Developmentally regulated conversion of surface-exposed chitin to chitosan in cell walls of plant pathogenic fungi. New Phytol. 156:103-112.

Epstein, L., Lusnak, K., and Kaur, S. 1998. Transformation-mediated developmental mutants of Glomerella graminicola. Fungal Genet. Biol. 23:189-203.

Fujiwara, M., Ichinomiya, M., Motoyama, T., Horiuchi, H., Ohta, A., and Takagi, M. 2000. Evidence that the Aspergillus nidulans class I and class II chitin synthase genes, $\operatorname{chs} C$ and $\operatorname{chs} A$, share critical roles in hyphal wall integrity and conidiophore development. J. Biochem. 127:359-366

Garcera-Teruel, A., Xoconostle-Cazares, B., Rosas-Quijano, R., Ortiz, L., Leon-Ramirez, C., Specht, C. A., Sentandreu, R., and Ruiz-Herrera, J. 2004. Loss of virulence in Ustilago maydis by Umchs6 gene disruption. Res. Microbiol. 155:87-97.

Georgopapadakou, N. H. 2001. Update on antifungals targeted to the cell wall: focus on beta-1,3-glucan synthase inhibitors. Exp. Opin. Invest. Drugs 10:269-280.
Gold, S. E., and Kronstad, J. W. 1994. Disruption of two genes for chitin synthase in the phytopathogenic fungus Ustilago maydis. Mol. Microbiol. 11:897-902.

Horiuchi, H., Fujiwara, M., Yamashita, S., Ohta, A., and Takagi, M. 1999. Proliferation of intrahyphal hyphae caused by disruption of $\operatorname{csmA}$, which encodes a class $\mathrm{V}$ chitin synthase with a myosin motor-like domain in Aspergillus nidulans. J. Bacteriol. 181:3721-3729.

Ichinomiya, M., Horiuchi, H., and Ohta, A. 2002. Different functions of the class I and class II chitin synthase genes, $\operatorname{ch} C$ and $\operatorname{chs} A$, are revealed by repression of $c h s B$ expression in Aspergillus nidulans. Curr. Genet. 42:51-58.

Kollar, R., Reinhold, B. B., Petrakova, E., Yeh, H. J., Ashwell, G., Drgonova, J., Kapteyn, J. C., Klis, F. M., and Cabib, E. 1997. Architecture of the yeast cell wall. Beta $(1 \rightarrow 6)$-glucan interconnects mannoprotein, beta( $1 \rightarrow 3)$-glucan, and chitin. J. Biol. Chem. 272:17762-1775.

Leach, J., Lang, B. R., and Yoder, O. C. 1982. Methods for selection of mutants and in vitro culture of Cochliobolus heterostrophus. J. Gen Microbiol. 128:1719-1729.

Lee, J. I., Choi, J. H., Park, B. C., Park, Y. H., Lee, M. Y., Park, H. M., and Maeng, P. J. 2004. Differential expression of the chitin synthase genes of Aspergillus nidulans, chs $A$, chs $B$, and $\operatorname{chs} C$, in response to developmental status and environmental factors. Fungal Genet. Biol. 41:635646.

Liu, H., Kauffman, S., Becker, J. M., and Szaniszlo, P. J. 2004. Wangiella (Exophiala) dermatitidis WdChs5p, a class V chitin synthase, is essential for sustained cell growth at temperature of infection. Euk. Cell 3:40-51.

Lu, S., Lyngholm, L., Yang, G., Bronson, C., Yoder, O. C., and Turgeon, B. G. 1994. Tagged mutations at the Tox1 locus of Cochliobolus heterostrophus by restriction enzyme-mediated integration. Proc. Natl. Acad. Sci. U.S.A. 91:12649-12653.

Madrid, M. P., Di Pietro, A., and Roncero, M. I. 2003. Class V chitin synthase determines pathogenesis in the vascular wilt fungus Fusarium oxysporum and mediates resistance to plant defence compounds. Mol. Microbiol. 47:257-266.

Mellado, E., Dubreucq, G., Mol, P., Sarfati, J., Paris, S., Diaquin, M., Holden, D. W., Rodriguez-Tudela, J. L., and Latge, J. P. 2003. Cell wall biogenesis in a double chitin synthase mutant (chsG/chsE) of Aspergillus fumigatus. Fungal Genet. Biol. 38:98-109.

Mendgen, K., and Deising, H. 1993. Infection structures of fungal plant pathogens - a cytological and physiological evaluation. New Phytol. 124:193-213.

Mendgen, K., Hahn, M., and Deising, H. 1996. Mechanisms and morphogenesis of penetration by plant pathogenic fungi. Annu. Rev. Phytopathol. 34:367-386.

Mio, T., Yabe, T., Sudoh, M., Satoh, Y., Nakajima, T., Arisawa, M., and Yamada-Okabe, H. 1996. Role of three chitin synthase genes in the growth of Candida albicans. J. Bacteriol. 178:2416-2419.

Miyazaki, A., and Ootaki, T. 1997. Multiple genes for chitin synthase in the zygomycete fungus Phycomyces blakesleeanus. J. Gen. Appl. Microbiol. 43:333-340.

Motoyama, T., Kojima, N., Horiuchi, H., Ohta, A., and Takagi, M. 1994. Isolation of a chitin synthase gene (chsC) of Aspergillus nidulans. Biosci. Biotechnol. Biochem. 58:2254-2257.

Motoyama, T., Fujiwara, M., Kojima, N., Horiuchi, H., Ohta, A., and Takagi, M. 1997. The Aspergillus nidulans genes chsA and chsD encode chitin synthases which have redundant functions in conidia formation. Mol. Gen. Genet. 253:520-528.

Munro, C. A., and Gow, N. A. 2001. Chitin synthesis in human pathogenic fungi. Med. Mycol. 39 (Suppl. 1):41-53.

Nagahashi, S., Sudoh, M., Ono, N., Sawada, R., Yamaguchi, E., Uchida, Y., Mio, T., Takagi, M., Arisawa, M., and Yamada-Okabe, H. 1995. Characterization of chitin synthase 2 of Saccharomyces cerevisiae. Implication of two highly conserved domains as possible catalytic sites. J. Biol. Chem. 270:13961-13967.

Nino-Vega, G. A., Carrero, L., and San-Blas, G. 2004. Isolation of the CHS4 gene of Paracoccidioides brasiliensis and its accommodation in a new class of chitin synthases. Med. Mycol. 42:51-57.

Ortoneda, M., Guarro, J., Madrid, M. P., Caracuel, Z., Roncero, M. I., Mayayo, E., and Di Pietro, A. 2004. Fusarium oxysporum as a multihost model for the genetic dissection of fungal virulence in plants and mammals. Infect. Immun. 72:1760-1766.

Pang, K. M., and Knecht, D. A. 1997. Partial inverse PCR: A technique for cloning flanking sequences. BioTechniques 22:1046-1048.

Rasmussen, J. B., and Hanau, R. M. 1989. Exogenous scytalone restores appressorial melanization and pathogenicity in albino mutants of Colletotrichum graminicola. Can. J. Plant Pathol. 11:349-352.

Roncero, C. 2002. The genetic complexity of chitin synthesis in fungi. Curr. Genet. 41:367-378

Ruiz-Herrera, J., Gonzalez-Prieto, J. M., and Ruiz-Medrano, R. 2002. 
Evolution and phylogenetic relationships of chitin synthases from yeasts and fungi. FEMS (Fed. Eur. Microbiol. Soc.) Yeast Res. 1:247-256.

Shaw, J. A., Mol, P. C., Bowers, B., Silverman, S. J., Valdivieso, M. H., Durán, A., and Cabib, E. 1991. The function of chitin synthases 2 and 3 in the Saccharomyces cerevisiae cell cycle. J. Cell Biol. 114:111-123.

Sietsma, J. H., and Wessels, J. G. H. 1994. Apical wall biogenesis. Pages 125-141 in: Growth, Differentiation and Sexuality. J. G. H. Wessels and F. Meinhardt, eds. Springer-Verlag, Berlin, Heidelberg.

Soulié, M. C., Perino, C., Piffeteau, A., Choquer, M., Malfatti, P., Cimerman, A., Kunz, C., Boccara, M., and Vidal-Cros, A. 2006. Botrytis cinerea virulence is drastically reduced after disruption of chitin synthase class III gene (Bcchs3a). Cell. Microbiol. 8:1310-1321.

Specht, C. A., Liu, Y., Robbins, P. W., Bulawa, C. E., Iartchouk, N., Winter, K. R., Riggle, P. J., Rhodes, J. C., Dodge, C. L., Culp, D. W., and Borgia, P. T. 1996. The chsD and chsE genes of Aspergillus nidulans and their roles in chitin synthesis. Fungal Genet. Biol. 20:153-167.

Stoldt, V. R., Sonneborn, A., Leuker, C. E., and Ernst, J. F. 1997. Efg1p, an essential regulator of morphogenesis of the human pathogen Candida albicans, is a member of a conserved class of bHLH proteins regulating morphogenetic processes in fungi. EMBO (Eur. Mol. Biol. Organ.) J. 16:1982-1991.

Takeshita, N., Yamashita, S., Ohta, A., and Horiuchi, H. 2006. Aspergillus nidulans class $\mathrm{V}$ and VI chitin synthases CsmA and CsmB, each with a myosin motor-like domain, perform compensatory functions that are essential for hyphal tip growth. Mol. Microbiol. 59:1380-1394.

Vidal-Cros, A., and Boccara, M. 1998. Identification of four chitin synthase genes in the rice blast disease agent Magnaporthe grisea. FEMS (Fed. Eur. Microbiol. Soc.) Microbiol. Lett. 165:103-109.

Vollmer, S. J., and Yanofsky, C. 1986. Efficient cloning of genes of Neurospora crassa. Proc. Natl. Acad. Sci. U.S.A. 83:4869-4873.
Wang, Z., Zheng, L., Liu, H., Wang, Q., Hauser, M., Kauffman, S., Becker, J. M., and Szaniszlo, P. J. 2001. WdChs2p, a class I chitin synthase, together with WdChs3p (class III) contributes to virulence in Wangiella (Exophiala) dermatitidis. Infect. Immun. 69:7517-7526.

Warren, L. H., Nicholson, R. L., Ullstrup, A. J., and Sharvelle, E. G. 1973. Observations of Colletotrichum graminicola on sweet corn in Indiana. Plant Dis. Rep. 57:143-144.

Weber, I., Assmann, D., Thines, E., and Steinberg, G. 2006. Polar localizing class $\mathrm{V}$ myosin chitin synthases are essential during early plant infection in the plant pathogenic fungus Ustilago maydis. Plant Cell $18: 225-242$.

Wedlich-Söldner, R., Bölker, M., Kahmann, R., and Steinberg, G. 2000. A putative endosomal t-SNARE links exo- and endocytosis in the phytopathogenic fungus Ustilago maydis. EMBO (Eur. Mol. Biol. Organ.) J. 19:1974-1986.

Wessels, J. G. H. 1993. Wall growth, protein excretion and morphogenesis in fungi. New Phytol. 123:397-413.

Wösten, H. A. B., Asgeirsdóttir, S. A., Krook, J. H., Drenth, J. H. H., and Wessels, J. G. H. 1994. The fungal hydrophobin Sc3p self-assembles at the surface of aerial hyphae as a protein membrane constituting the hydrophobic rodlet layer. Eur. J. Cell Biol. 63:122-129.

Zhang, Z., Hall, A., Perfect, E., and Gurr, S. J. 2000. Differential expression of two Blumeria graminis chitin synthase genes. Mol. Plant Pathol. $1: 125-138$.

\section{AUTHOR-RECOMMENDED INTERNET RESOURCE}

Cambridge Medical Research Council Laboratory of Molecular Biology Myosin Home Page: www.proweb.org/myosin 